\title{
RESEARCH
}

Open Access

\section{Ibuprofen prevents progression of ataxia telangiectasia symptoms in ATM-deficient mice}

\author{
Chin Wai Huil ${ }^{1+}$, Xuan Song ${ }^{1 \dagger}$, Fulin Ma ${ }^{1}$, Xuting Shen ${ }^{1,2}$ and Karl Herrup ${ }^{1 *}(\mathbb{D}$
}

\begin{abstract}
Background: Inflammation plays a critical role in accelerating the progression of neurodegenerative diseases, such as Alzheimer's disease (AD) and ataxia telangiectasia (A-T). In A-T mouse models, LPS-induced neuroinflammation advances the degenerative changes found in cerebellar Purkinje neurons both in vivo and in vitro. In the current study, we ask whether ibuprofen, a non-steroidal anti-inflammatory drug (NSAID), can have the opposite effect and delay the symptoms of the disease.

Methods: We tested the beneficial effects of ibuprofen in both in vitro and in vivo models. Conditioned medium from LPS stimulated primary microglia (LM) applied to cultures of dissociated cortical neurons leads to numerous degenerative changes. Pretreatment of the neurons with ibuprofen, however, blocked this damage. Systemic injection of LPS into either adult wild-type or adult $\mathrm{Atm}^{-1-}$ mice produced an immune challenge that triggered profound behavioral, biochemical, and histological effects. We used a 2-week ibuprofen pretreatment regimen to investigate whether these LPS effects could be blocked. We also treated young presymptomatic Atm ${ }^{-1-}$ mice to determine if ibuprofen could delay the appearance of symptoms.
\end{abstract}

Results: Adding ibuprofen directly to neuronal cultures significantly reduced LM-induced degeneration. Curiously, adding ibuprofen to the microglia cultures before the LPS challenge had little effect, thus implying a direct effect of the NSAID on the neuronal cultures. In vivo administration of ibuprofen to $\mathrm{Atm}^{-1-}$ animals before a systemic LPS immune challenge suppressed cytological damage. The ibuprofen effects were widespread as microglial activation, p38 phosphorylation, DNA damage, and neuronal cell cycle reentry were all reduced. Unfortunately, ibuprofen only slightly improved the LPS-induced behavioral deficits. Yet, while the behavioral symptoms could not be reversed once they were established in adult $\mathrm{Atm}^{-/-}$animals, administration of ibuprofen to young mutant pups prevented their symptoms from appearing.

Conclusion: Inflammatory processes impact the normal progression of A-T implying that modulation of the immune system can have therapeutic benefit for both the behavioral and cellular symptoms of this neurodegenerative disease.

Keywords: Ataxia telangiectasia, Ibuprofen, Anti-inflammatory, Microglia, Purkinje cell

\footnotetext{
* Correspondence: herrup@ust.hk

${ }^{+}$Chin Wai Hui and Xuan Song contributed equally to this work.

'Division of Life Science and State Key Laboratory of Molecular

Neurobiology, Hong Kong University of Science and Technology, Clear Water

Bay, Kowloon, Hong Kong

Full list of author information is available at the end of the article
}

(c) The Author(s). 2018 Open Access This article is distributed under the terms of the Creative Commons Attribution 4.0 International License (http://creativecommons.org/licenses/by/4.0/), which permits unrestricted use, distribution, and reproduction in any medium, provided you give appropriate credit to the original author(s) and the source, provide a link to the Creative Commons license, and indicate if changes were made. The Creative Commons Public Domain Dedication waiver (http://creativecommons.org/publicdomain/zero/1.0/) applies to the data made available in this article, unless otherwise stated. 


\section{Background}

Ataxia telangiectasia (A-T) is a neurodegenerative disease of childhood with a prevalence between 1 in 40,000 and 1 in 100,000 people worldwide. It results from the mutation of a single gene, A-T mutated (ATM), whose gene product is a large kinase of the PI3K family. A-T symptoms include a progressive neuronal loss, ataxia, cancer susceptibility, hypersensitivity to ionizing radiation, immunodeficiency, and sterility [1-3]. The particular type of immunodeficiency found in A-T is life-threatening for nearly one third of A-T patients because of the resulting increase in susceptibility to infections, particularly of the lung [4]. In the context of a neurodegenerative disease, the co-occurrence of these immune problems is noteworthy since the immune and nervous system maintain extensive communication through the entire lifespan $[5,6]$. The development of the central nervous system (CNS) can be significantly altered by immune challenges, and in the adult, unchecked inflammatory signals and the resulting cytokine imbalances usually lead to fatigue, impaired cognition, as well as slower healing and recovery after nerve injury [7-12]. Chronic inflammation is found in many age-related disorders, where it raises the susceptibility to cardiovascular difficulties, asthma, and cancer [13]. Many late-onset neurodegenerative diseases are also associated with a long-term inflammatory process, and in vitro studies suggest that this process involves the release of a large profile of pro-inflammatory cytokines $[14,15]$ and reactive oxygen species (ROS) [16, 17]. In A-T patients, sustained immune challenges, including bacterial infections and chronic inflammation, greatly contribute to the development of disease pathology $[18,19]$. Furthermore, reports from clinical trials have shown that glucocorticoids, powerful anti-inflammatory hormones, are able to ameliorate the symptoms of A-T [20, 21]. The finding of peripheral immune deficiency in $\mathrm{A}-\mathrm{T}$ patients is well established and highlights the contribution of the immune system to the symptoms of A-T. The contribution of the immune system, in particular, the microglia of the brain's innate immune system, to the neurological and neuropathological abnormalities of A-T remains less certain.

Previous studies in experimental systems have shown that microglia have a significant impact on the process of neurodegeneration in A-T in both mouse and Drosophila models $[22,23]$. Studies from our lab have found that systemic LPS administration triggers exaggerated neuronal damage in both short (1 week) [24] and long (1 month) [25] time frames. In this study, we investigated the effect of ibuprofen, a non-selective non-steroidal anti-inflammatory drug (NSAID). NSAIDs are regarded as non-selective COX inhibitors to reduce neuroinflammation, promote neuronal survival, and improve cognitive function in rodent models of different neurodegenerative conditions-Alzheimer's disease $(\mathrm{AD})$, traumatic brain injury, and exaggerated excitotoxicity [26-28]. Epidemiological studies suggest that they are protective in human AD [29] and are of significant benefit in mouse models of AD if they are administered before symptoms appear [29, 30]. Unfortunately, prospective AD clinical trials showed little efficacy in subjects with mild dementia, but two human studies have shown that ibuprofen is able to modify the progression of mild $\mathrm{AD}$ [31] and can directly block LPS-induced microglial activation and impairments of spatial working memory [32]. These human studies have been replicated in mouse models of $\mathrm{AD}$ [30, 33-35] with the exception of the 5XFAD mouse [36].

Here, we report that in vitro ibuprofen pretreatment offers significant protection. In vivo $\mathrm{Atm}^{-/-}$animals pretreated with ibuprofen for 2 weeks are less vulnerable to LPS-induced motor dysfunction, have less Purkinje cell damage, and show reduced microglial activation. In the absence of an exogenous immune challenge, ibuprofen treatment of young presymptomatic $\mathrm{Atm}^{-1-}$ animals improved multiple classic histopathological features of the $\mathrm{Atm}^{-/-}$brain. These data support a potential role for ibuprofen in preventing the development of neuropathological symptoms in A-T. While ibuprofen did not improve the motor performance of the $\mathrm{Atm}^{-/-}$mice in the treatment regimen we used, it proved to be effective in preventing new pathological signs from developing. Taken together, our data suggest that administration of the NSAID ibuprofen can impact the progression of A-T at both the cellular and organismal level.

\section{Methods and materials}

\section{Atm-deficient mice}

A breeding colony of mice with a targeted disruption of the Atm gene Atm ${ }^{\text {tm } 1 A w b}$ [37] was obtained from The Jackson Laboratory (Bar Harbor, ME). Generation of mutants was achieved through the mating of heterozygous $\mathrm{Atm}^{+/-}$males and $\mathrm{Atm}^{+/-}$females. The mice were maintained on a $129 / \mathrm{SvJ}$ genetic background. Genotyping was performed on extracted tail DNA using PCR techniques that were described previously [37]. All animal experimental protocols were approved both by the Animal Ethics Committee at HKUST and their care that was in accord with the institutional and Hong Kong guidelines.

\section{Injections with lipopolysaccharide}

Lipopolysaccharide (LPS, Escherichia coli serotype 055:B5) was purchased from Sigma-Aldrich (L2880, St. Louis, MO, USA), dissolved in distilled water, and stored at $-20{ }^{\circ} \mathrm{C}$. Adult mice (3-month-old) of $\mathrm{Atm}^{+/+}$and $\mathrm{Atm}^{-1-}$ genotypes were given daily intraperitoneal injections of LPS ( $1 \mathrm{mg} / \mathrm{kg}$ for a period of 4 days) in keeping with our previous protocol [24]. A control group was treated on the same schedule with injection of filtered saline only. Mice were killed on the fifth day, $24 \mathrm{~h}$ after the last injection. Mice in both groups were monitored 
carefully for signs of sickness or distress during the entire period. Following sacrifice, the brains were dissected and the tissues prepared as described below.

\section{Ibuprofen oral administration}

Commercial ibuprofen was purchased from CVS pharmacy and kept at room temperature. Two treatment groups were established. In the first group, the dose of ibuprofen used $(62.5 \mathrm{mg} / \mathrm{kg}$ ) [38] was orally administrated to P10 mice of $\mathrm{Atm}^{+/+}$and $\mathrm{Atm}^{-/-}$genotypes once per day for 2 weeks to investigate whether ibuprofen could block the development of the A-T symptoms that normally appear during this early postnatal period. A control group of the same age was untreated. Mice were killed as above immediately after receiving the last oral suspension. A second group of 3-month-old adult animals $\left(\mathrm{Atm}^{+/+}\right.$and $\mathrm{Atm}^{-/-}$genotypes) were administrated ibuprofen $(0.5 \mathrm{mg} / \mathrm{ml}$ of drinking water, calculated based on the amount of water consumed by mice and administration dose as mentioned above) for 2 weeks to investigate whether ibuprofen could prevent the progression of A-T symptoms. Mice then received daily intraperitoneal injections of LPS $(1 \mathrm{mg} / \mathrm{kg})$ for 4 days with or without oral administration of ibuprofen $(62.5 \mathrm{mg} / \mathrm{kg})$. Mice were killed on the fifth day, $24 \mathrm{~h}$ after the last injection. During the treatment, mice were monitored carefully.

\section{Rotarod test}

After treatment with LPS or/and ibuprofen, mice were subjected to rotarod testing without initial training to measure motor coordination but not motor learning. Mice were placed on the rotating rod for $1 \mathrm{~min}$ then tested for coordination by measuring the time they were able to remain on the rod as the rotation speed accelerated (4-40 rpm with an acceleration of $4 \mathrm{rpm} / 10 \mathrm{~s}$ ). The experimental groups were randomized in different positions while running on the rods. The rotarod software (ANY-maze Behavior Tracking Software; Stoelting Co., Wood Dale, IL) calculates the number of times the animal complete an entire rotation of $360^{\circ}$ during the observation period.

\section{Open field test}

The open field test is used to determine gross locomotor activity and exploration habits. Mice were introduced singly into a square arena $(50 \times 50 \mathrm{~cm})$ bounded by tall walls with a defined (but invisible) center area of $25 \times$ $25 \mathrm{~cm}$. Mice were allowed to acclimate to the testing room overnight before training. Mice were placed in the center of the square arena and allowed to freely move for 10 min while being tracked by an automated tracking system (Stoelting ANY-maze, Wood Dale, U.S.A). After 4 to 5 days of treatment with LPS or/and ibuprofen administration, the mice were tested every 2 days. Mice were killed immediately after the third test on the fifth day (Fig. 3c). The experimental groups were randomized in different open field platforms.

\section{Tissue preparation and histology}

Animals were deeply anesthetized with Avertin $(0.02 \mathrm{cc} / \mathrm{g}$ body weight) and perfused with cold PBS for $3 \mathrm{~min}$. After perfusion, the brain was dissected out and bisected along the midline. Half of the brain was stored at $-80{ }^{\circ} \mathrm{C}$ for future use. Half was fixed in $4 \%$ paraformaldehyde (PFA, Sigma-Aldrich) at $4{ }^{\circ} \mathrm{C}$ overnight. After washing twice with PBS, the brain was transferred to $30 \%$ sucrose solution and incubated at $4{ }^{\circ} \mathrm{C}$ overnight for cryoprotection. Brains were then embedded in OCT and frozen quickly in powdered dry ice. Ten micron cryostat sections were cut and allowed to air dry on pre-coated SuperPlus glass slides.

\section{Primary microglia cell culture and preparation of LPS conditioned medium}

Primary microglia were isolated from C57BL/6J mice using our established protocol [39]. Briefly, a mixed glial cell population was obtained from P2-P5 pups and was cultured for 2 weeks in DMEM medium supplemented with $10 \% \mathrm{FBS}$ and $1 \%$ pen/strep. Pure microglia were obtained by shaking at $37{ }^{\circ} \mathrm{C}$ for $4 \mathrm{~h}$. LPS conditioned medium (LM) was prepared by incubating microglia cells at a density of 50,000 per well in a 24-well plate in Neurobasal medium containing $10 \mu \mathrm{g} / \mathrm{ml}$ LPS for 2 days. In another group, ibuprofen $(200 \mu \mathrm{M})$ was added to the microglial cultures for $6 \mathrm{~h}$ and before treating them with $10 \mu \mathrm{g} / \mathrm{ml}$ LPS for 2 days. A control group was treated in Neurobasal medium without LPS (MM). After the two-day treatment, the medium was obtained and centrifuged to remove cells and debris, then used for neuronal treatment within $24 \mathrm{~h}$. Microglial cells were washed by PBS once and lysed for further studies. THP-1 cells were cultured in RPMI 1640 medium with $10 \%$ FBS and $0.05 \mathrm{mM} \beta$-mercaptoethanol for routine passage. $\beta$-mercaptoethanol was removed from the medium when cells were treated with stimulus.

\section{Primary cortical neuronal culture}

Embryonic cortical neurons were isolated by standard procedures [40]. All cultures were grown for a minimum of 13 days in vitro (DIV) before any treatment. Cultures were then pretreated with ibuprofen $(80,120$, and $200 \mu \mathrm{M})$ or DMSO for $24 \mathrm{~h}$ after which MM or LM (12.5\% volume/volume) was added for another $48 \mathrm{~h}$. For histological studies, cells were washed with PBS and fixed in $4 \%$ PFA for $15 \mathrm{~min}$. After rinsing in PBS, cells were stored in $0.1 \%$ PFA if longer-term storage was required. 


\section{Antibodies for histological and Western studies} PCNA, p38, phospho-p38 (Thr180/Tyr182), ERK, phosphoERK (Thr202/Tyr204), JNK, phospho-JNK (Thr183/Tyr185), NFкB p105/50, NFкB p65, phospho-NFкB p65 (Ser536), RelB, Akt, phospho-Akt (Ser473), and phospho-Akt (Thr308) antisera were purchased from Cell Signaling Technology (Danvers, MA, USA); CD45, Iba-1, GFAP, $\gamma$-H2AX, HDAC4, MAP2, GAPDH, 8-oxoguanine, and Ki67 antisera were purchased from Abcam (Cambridge, MA, USA); and cyclin A1 and c-Rel antisera were purchased from Santa Cruz Biotechnology (Dallas, Texas, USA). Secondary antisera conjugated with fluorescent Alexa dye 488 and 647 and Cy3 were purchased from Life Technologies and Jackson ImmunoResearch (West Grove, PA, USA). HRP-conjugated secondary antibodies were purchased from Cell Signaling Technology and Life Technologies.

\section{Annexin $\mathrm{V} /$ propidium iodide apoptotic assay}

Apoptotic and necrotic events in cell culture were assayed by annexin V/propidium iodide (V13245, Life Technologies) following the manufacturer's protocol. In brief, coverslips were washed with cold PBS and immediately incubated with working solution containing propidium iodide and Alexa Fluor 488 annexin V diluted in an annexin-binding buffer for $15 \mathrm{~min}$. After washing with annexin-binding buffer, coverslips were mounted with anti-fading fluorescence media from Vector Laboratories (Burlingame, CA, USA).

\section{Immunocytochemistry and immunofluorescence}

Immunocytochemistry was performed on mouse brain cryosections or PFA fixed cells according to standard methods [25]. Briefly, sections or cells were blocked in PBS containing $0.3 \%$ Triton X-100 and 10\% donkey serum for $1 \mathrm{~h}$ in room temperature. They were then incubated in the same solution with primary antibodies overnight at $4{ }^{\circ} \mathrm{C}$ and immersed in fluorescent secondary antibodies for $1 \mathrm{~h}$ at room temperature. After counterstaining with DAPI for $5 \mathrm{~min}$, all sections were mounted with anti-fading fluorescence media (Vector Laboratories) under a glass coverslip. All coverslips were mounted on glass slides. Experiments were the results of triplicate cultures established on separate days.

\section{Cell counting and Iba1/GFAP analysis}

The method for cell counting was described previously [24]. Briefly, five fields were randomly chosen at $\times 200$ final magnification on an Olympus fluorescent microscope and every neuron was counted in the images from immunohistochemistry and immunocytochemistry. The percentage of the positive PCs and cultured neurons with markers of interest were counted and expressed as a fraction of the total MAP2-positive PCs/neurons. For cell counting in the frontal cortex, total MAP2-labeled neurons within layers II to $\mathrm{V}$ that co-localized with markers of interest were counted at the same magnification. Iba1 and GFAP signals were analyzed in three images/animal using ImageJ software (National Institutes of Health). The threshold value was set at $\sim 40$ in the measurement tool, and the percentages of Iba1/GFAP occupied areas in each image were measured. Iba1 and GFAP staining factors were normalized to the untreated $\mathrm{Atm}^{+/+}$group and expressed in a normalized ratio.

\section{Quantitative real-time PCR}

Microglia, THP-1 cells, and mouse cerebellar tissues were lysed in buffer containing 3\% $\beta$-mercapethanol; total RNA was then extracted and reverse-transcribed as previously described [40]. Real-time PCR was performed using SYBR Premix Ex Taq (Takara Biotechnology) in the 7500 Real-Time PCR System (Applied Biosystems, Life Technologies). ROX II was applied as the reference dye. The sets of primers used are listed in Tables 1 and 2. Expression levels of Gapdh or 18SRNA were used for normalization.

\section{Western blot analysis}

Western blots were performed on mouse cerebellar tissues according to standard methods [40]. Tissue lysates were prepared in RIPA lysis buffer (Millipore, Billerica, MA, U.S.A) containing protease and phosphatase inhibitors (Roche, Grenzacherstrasse, Basel, Schweiz). Protein samples were separated by gel electrophoresis, transferred to nitrocellulose membrane (Bio-Rad), and blocked with 5\% albumin bovine serum (Sigma-Aldrich) or 5\% milk (Bio-Rad). After incubation with primary antibodies at room temperature overnight and then secondary antibodies at room temperature for $1 \mathrm{~h}$, protein signals were visualized using ECL substrate reagents (Thermo Scientific, Waltham, MA, USA). The intensities of the bands were quantified by ImageJ and normalized to the GAPDH level.

\section{ELISA}

ELISA kits against TNF $\alpha$ (\#DY410) and IL1 $\beta$ (\#DY401) were purchased from $R \& D$ systems. Cerebellar protein

Table 1 Primer for Mus musculus

\begin{tabular}{lll}
\hline & Forward & Reverse \\
\hline Ym1 & cagctgggatcttcctacca & attctgcattccagcaaagg \\
Trem2 & ctggaaccgtcaccatcact & aggctagaggtgacccacag \\
$\| 1 \beta$ & gccacctttgacagtgatgag & aaggtccacgggaaagacac \\
Tnfa & aggcactcccccaaaagatg & ccacttggtggtttgtgagtg \\
iNOS & acagggagaaagcgcaaaac & gaacattctgtgctgtcccag \\
$\| 6$ & agacaaagccagagtccttcag & tgtgactccagcttatctcttgg \\
CCl2 & gctgtagttttgtcaccaagctc & agtgcttgaggtggttgtgg \\
$\| 12$ & ctcacccttaggacccagga & ctcacccttaggacccagga \\
Gapdh & ggagaaacctgccaagtatga & ggtcctcagtgtagcccaag \\
\hline
\end{tabular}


Table 2 Primer pairs for Homo sapiens

\begin{tabular}{lll}
\hline & Forward & Reverse \\
\hline NFkB1 (P50/P105) & cctggatgactcttgggaaa & tcagccagctgttcatgtc \\
RelA (P65) & ggcgagaggagcacagatac & ctgatagcctgctccaggtc \\
COX2 & ctgttgcggagaaaggagtc & tcatggaagatgcattggaa \\
IL1ß & cagccaatcttcattgctca & gcatcttcctcagcttgtcc \\
TNFa & tccttcagacaccctcaacc & aggccccagtttgaattctt \\
IL6 & aaagaggcactggcagaaaa & caggggtggttattgcatct \\
IL8 & ggtgcagttttgccaaggag & ttccttggggtccagacaga \\
CD45 & ggcagacaccagaattggtt & gggagaaagggagtggaaag \\
CD11B & agaacaacatgcccagaacc & gcggtcccatatgacagtct \\
SOCS3 & caagaagccaaccaggagag & gttcagcattcccgaagtgt \\
18SRNA & tgcatgtctaagtacgcacggcc & gatagggcagacgttcgaatggg \\
\hline
\end{tabular}

lysate was diluted in 1:10, and protein levels of TNF $\alpha$ and IL1 $\beta$ were determined according to the manufacturer's protocol. Both forms of IL- $1 \beta$, pro-IL- $1 \beta$, and cleaved-IL-1 $\beta$ were detected by the ELISA kit. However, the signals were more specific to the cleaved form. Quantification was performed based on the cleaved form of IL-1 $\beta$.

\section{Statistics}

Student's unpaired $t$ test and two-way ANOVA with Bonferroni post hoc test (Prism, GraphPad software, Version 7) were used to determine the differences in values between different groups. $p<0.05$ was considered statistically significant. These are the symbols used for significance in the figures: $* / \#: p<0.05, * * / \# \#: p<0.01$, **:*\#\#\#: $p<0.001$.

\section{Study approval}

All animals were housed at the Animal and Plant Care Facility of Hong Kong University of Science and Technology. All procedures involving animals were approved by the Department of Health, Hong Kong. In the writing of the article, every effort has been made to follow the ARRIVE guidelines (https://www.nc3rs.org.uk/arrive-guidelines).

\section{Results}

Microglia-mediated immune challenge contributes to the neuronal damage in vitro

Previous studies in our lab have found that an LPS (lipopolysaccharide) immune challenge significantly exaggerates neuronal damage in both the short and long-term $[24,25]$. To replicate this effect in an in vitro system, we established enriched cultures of microglia from wild-type mice, applied LPS (lipopolysaccharide) directly to the cultures $(10 \mu \mathrm{g} / \mathrm{ml}$ for $48 \mathrm{~h})$, harvested the medium, and applied it to separate cultures of the neuron. This treatment was effective as the LPS-conditioned medium (LM) caused the exposed neuronal cells to undergo a marked morphological change (Fig. 1). In addition, the neurons demonstrated enhanced stress. They showed significant cell loss as measured by decreased MAP2 counts and increased cell cycle activity as measured by both enhanced Ki67 and cyclin D staining. This was not an effect of residual LPS in the LM; direct treatment of neuronal cultures with $10 \mu \mathrm{g} / \mathrm{ml}$ LPS (Table 3) failed to induce any of these symptoms of neuronal damage. A measurable neuronal response was also seen with conditioned medium from un-stimulated microglial cultures (MM), as high concentrations of MM (12.5\%) induced a slight degree of damage to the cultured neurons [41]. Nonetheless, neurotoxicity was significantly exaggerated when microglia were pretreated with LPS; this shows that under a specific immune challenge, more harmful substances were released into the medium [42]. To more closely mimic the chemistry of the human immune response, we repeated these experiments with the human THP-1 monocyte cell line instead of primary mouse microglia [43-45]. This treatment also upregulated the expression of pro-inflammatory genes (Additional file 1: Figure S1). Further, just as with the medium from primary mouse microglial cells, both unstimulated (TM) and LPS-stimulated (LM) conditional media from THP-1 cells caused neurotoxicity and ectopic cell cycle reentry (Additional file 2: Figure S2A-N).

Given the fact that direct application of LPS does not damage cells in neuronal cultures, these data demonstrate that it is the products of microglia, responding to the LPS challenge, that cause the damage. To determine the nature of the neurodegeneration caused by conditioned media, neurons were stained with annexin V/propidium iodide [46]. With these reagents, apoptotic cells fluoresce green while cells that die by non-apoptotic means show red plus green fluorescence. Live cells show little or no fluorescence (Fig. 2j-o). In cultures treated only with $\mathrm{MM}$, cells were only lightly labeled with annexin $\mathrm{V}$ (green) suggesting that the deaths were largely apoptotic events. No obvious cell death of any kind was identified in control groups (Fig. 2j). Under $12.5 \%$ LM treatment, however, most cells showed strong green plus red signals (Fig. 2l). This suggests that LM kills neurons via a non-apoptotic, possibly necrotic process (see also Fig. 1).

\section{Ibuprofen attenuates inflammatory stress and cell death}

To determine whether ibuprofen could be effective at reducing the complex inflammatory stress caused by activation of the innate immune system, DIV14 cortical neurons were pretreated with ibuprofen $24 \mathrm{~h}$ before the MM or LM challenge. Cells were then stained with cell cycle markers to assess neuronal stress. ANOVA revealed a significant effect of ibuprofen treatment on ectopic cell cycle reentry with significant conditioned medium cross ibuprofen interaction. (Fig. 1 and Additional file 2: Figure S2A-N) 


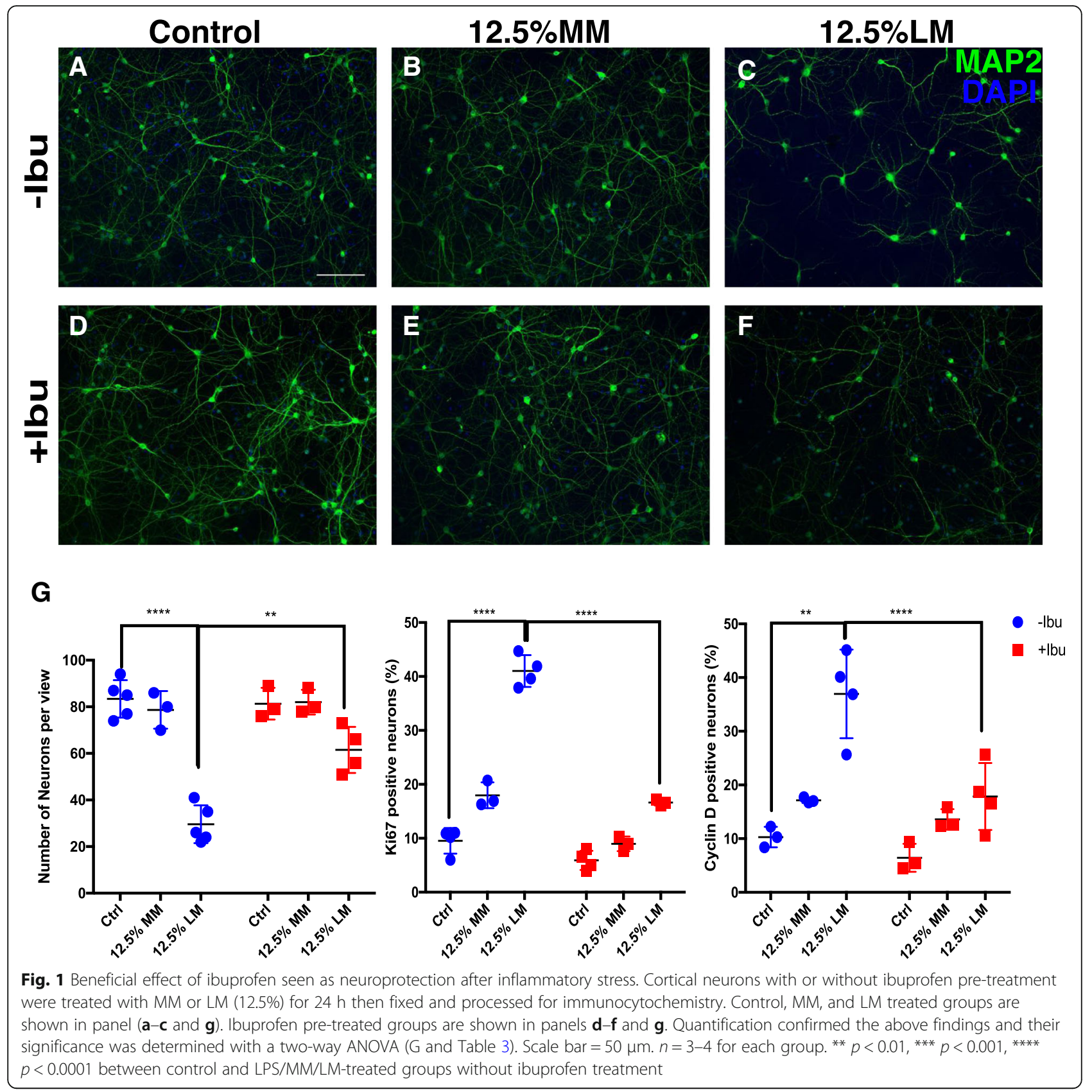

Ibuprofen treatment alone did not induce any significant changes in control cultures or neuronal cultures subjected to direct LPS treatment (Fig. 1 and data not shown). In the more complex environment of LM conditioned medium, however, post hoc tests showed that ibuprofen treatment suppressed LPS-induced neuronal cell cycle events (CCEs) (Fig. 1g, Additional file 2: Figure S2I-N and Table 3). Notably, $120 \mu \mathrm{M}$ ibuprofen significantly reduced neuronal apoptosis as measured by the annexin V/PI signal (Fig. 2m-o). Thus, when applied directly to neurons, ibuprofen has a significant neuroprotective effect against LM-induced neuroinflammation.
Interestingly, ibuprofen pretreatment of the microglial themselves did not block their activation by LPS nor their ability to produce neurotoxic material in their medium (Fig. 2a-i). LPS induced a substantial morphological change from a resting ramified state to a more amoeboid-like active stage. To our surprise, however, pretreating the microglia with ibuprofen for $12 \mathrm{~h}$ (Fig. 2c, d, g, h) did not block the effect of LPS and had little impact on the activation of the immune pathway in microglia (Fig. 2e-i). After LPS stimulation, the percentage of cells with an activated NF- $\mathrm{KB}$ pathway, as measured by the translocation of p65 from the 
Table 3 Two-way ANOVAs analysis for cyclin D and Ki67 counts in all treatment groups

\begin{tabular}{|c|c|c|}
\hline & $\begin{array}{l}\text { Cyclin D } \\
p \text { value }\end{array}$ & $\begin{array}{l}\text { Ki67 } \\
p \text { value }\end{array}$ \\
\hline Control vs LPS & $<0.05$ & $>0.05$ \\
\hline Control vs $12.5 \%$ LM & $<0.001$ & $<0.0001$ \\
\hline \multicolumn{3}{|l|}{$12.5 \%$ LM vs $12.5 \%$ LM } \\
\hline$+200 \mu \mathrm{M}$ ibuprofen & $<0.0001$ & $<0.0001$ \\
\hline Control vs $6.25 \%$ LM & $<0.001$ & $<0.001$ \\
\hline \multicolumn{3}{|l|}{$6.25 \%$ LM Vs 6.25\% LM } \\
\hline$+200 \mu \mathrm{M}$ ibuprofen & $<0.001$ & $<0.001$ \\
\hline Control vs 6.25\% MM & $<0.05$ & $>0.05$ \\
\hline \multicolumn{3}{|l|}{$6.25 \%$ MM Vs 6.25\% MM } \\
\hline 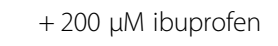 & $>0.05$ & $>0.05$ \\
\hline Control vs $12.5 \% \mathrm{MM}$ & $<0.05$ & $<0.05$ \\
\hline \multicolumn{3}{|l|}{$12.5 \% \mathrm{MM}$ Vs $12.5 \% \mathrm{MM}$} \\
\hline 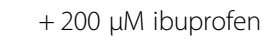 & $<0.05$ & $<0.05$ \\
\hline
\end{tabular}

Samples that are statistically significant were shown in boldface in the table

cytoplasm to the nucleus, significantly increased, but pretreatment with ibuprofen failed to block this response. We speculate that, given the long-term nature of our assay, these results are most likely due to the chronic versus acute nature of the inflammatory response that we measured [47]. Our data therefore demonstrate that ibuprofen can provide immunoprotection to neurons if applied directly and this effect is independent of any direct effect of ibuprofen on LPS-stimulated microglia.

\section{Ibuprofen improves LPS-induced symptoms in $\mathrm{Atm}^{-/-}$ mice}

In vivo ATM deficiency exacerbates the neuronal damage induced by LPS-triggered bouts of neuroinflammation [24]. To test the effects of ibuprofen on this response, we administered LPS by i.p. injection to 3-month-old $\mathrm{Atm}^{+/+}$and $\mathrm{Atm}^{-1-}$ mice for 4 days. Mice from all treatment groups were then subjected to behavioral testing. Two days after its initiation, ANOVA revealed significant effects of the LPS treatment (distance traveled: $[F(1,27)=12.12, p=0.0017]$, body rotation: $[F(1,27)=8.91, p=0.0114])$ and genotype (distance traveled: $[F(1,27)=20.35, p=0.0001]$, body rotation: $[F(1,27)=36.37, p<0.0001])$. LPS injection led to reduced motor behavior as seen by both reduced total travel distance $\left(\mathrm{Atm}^{+/+}: p<0.05 ; \mathrm{Atm}^{-/-}: p<0.01-\right.$ Fig. 3a) and reduced number of body rotations (Fig. 3b). The LPS-induced behavioral deficiency, observed at day three, remained stable at day five in the wild-type $\left(\mathrm{Atm}^{+/+}\right)$animals, but continued to decline in the $\mathrm{Atm}^{-/-}$mutant mice (distance traveled: $[F(1,27)=14.48, p=0.0007]$, post hoc test: $p<0.01$; body rotation: $[F(1,27)=23.35, p=0.0004]$, post hoc test: $p<0.01$ ) (Fig. 3a-b). Thus, an LPS challenge worsens many of the AT neurological phenotypes and exacerbates the subtle motor deficiency of the AT mouse model.

We then tested whether ibuprofen might have beneficial effects in blunting an LPS-induced inflammatory challenge in vivo. The experimental procedure is diagrammed in Fig. 3c. Three-month-old $\mathrm{Atm}^{+/+}$and $\mathrm{Atm}^{-1}$ - animals were administered ibuprofen $(0.5 \mathrm{mg} / \mathrm{ml}$ in their drinking water) for 2 weeks. Animals were subjected to rotarod and open field tests after 1 week of ibuprofen treatment. One week later, we began a daily regimen of intraperitoneal injections of LPS $(1 \mathrm{mg} / \mathrm{kg})$ for 4 days. During this final phase, we tested mice in the open field every 2 days. We confirmed the compromised motor performance of the $\mathrm{Atm}^{-/-}$animals on the rotarod (Fig. $3 \mathrm{~d}-[F(1,64)=7.80, p=0.0069]$, post hoc test: $p<0.05$ by ANOVA) and open-field tests (Fig. 3a- $[F(1,27)=14.05, p=0.0009]$, post hoc test: $p<0.05)$ and showed that LPS injection further degraded the performance of both mutant and wild-type animals in the open field test. Unfortunately, a 2-week ibuprofen treatment of $\mathrm{Atm}^{+/+}$mice was unable to block the LPS effect, consistent with its modest long-term effect on the microglial reaction. Although the motor behavior performance of $\mathrm{Atm}^{-/-}$animals continued to decline, ibuprofen led to a modest lessening of the LPS-induced deterioration (Fig. 3e). There was little effect of the NSAID on the baseline behavior of $\mathrm{Atm}^{-/-}$mice (Fig. 3d, e) although open field behavior improved slightly on day five.

\section{Ibuprofen promotes anti-inflammatory and anti-oxidative effects in ATM-deficient conditions}

While the behavioral deficits were largely refractory to change, we found important anti-inflammatory and anti-oxidative effects of ibuprofen at the cellular level. At this resolution, the effects of chronic LPS treatment on brain microglia were apparent, as assessed by Iba1 staining and morphology (Fig. 4i). LPS administration significantly induced microglia activation in both wild-type and $\mathrm{Atm}^{-/-}$mice. We quantified the Iba1 staining factor by measuring the area occupied by Iba1-positive glia and dividing by the total area of the image. The deep cerebellar nuclei (DCN) represent the final output of the cerebellar circuitry and the hyperexcitability of this region leads to cerebellar ataxia when there is a loss of inhibitory inputs from cortical Purkinje cells [48]. We therefore focused our analysis on this region. ANOVA revealed a significant effect of LPS treatment on both genotypes $\left(\mathrm{Atm}^{+/+}:[F(1,12)=33.46\right.$, $p<0.0001]$, Atm $\left.^{-/-}:[F(1,12)=125.93, p<0.0001]\right)$ but the effect of ibuprofen was seen only in $\mathrm{Atm}^{-/-}$animals $[F(1,12)=19.61, p=0.0008]$. Iba1 microglial staining increased after LPS injection, and this reaction could be suppressed by ibuprofen treatment in both genotypes 

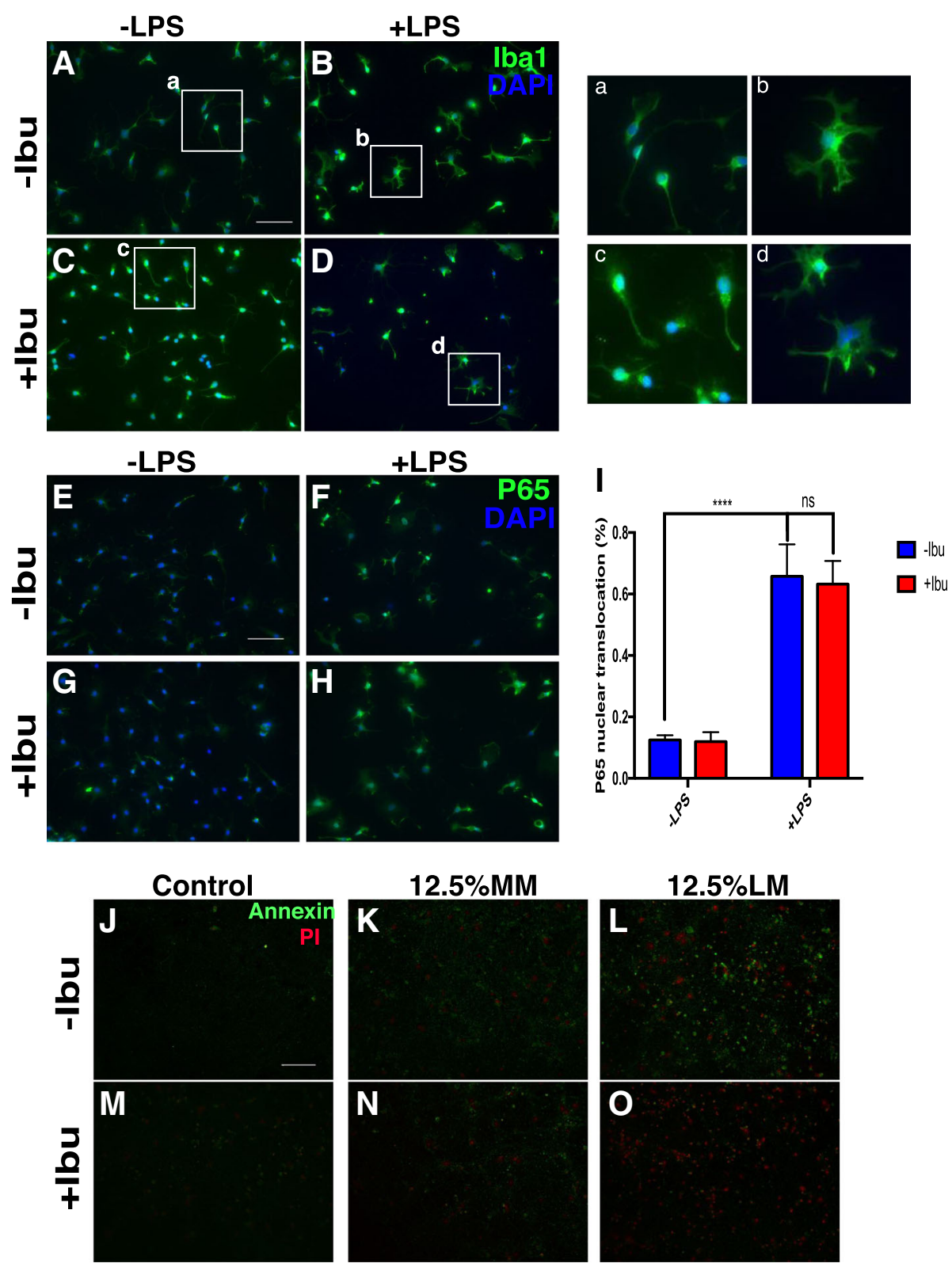

Fig. $\mathbf{2}$ a, b LPS challenge dramatically changes the morphology of microglia and induces the activation of the NF-KB pathway $(\mathbf{e}, \mathbf{f}$, and i). $\mathbf{c}, \mathbf{d}$, $\mathbf{g}$-i lbuprofen did not block the activation of microglia after LPS stimulation. $\mathbf{j}-\mathbf{o}$ Both annexin $\mathrm{V}$ and PI signals accumulated in neuronal culture when treated with LM. Ibuprofen pretreatment significantly blocked both apoptotic and necrotic processes. Scale bar $=50 \mu \mathrm{m}$. $n=4$ for each group. ${ }^{* *} p<0.01,{ }^{* * *} p<0.001,{ }^{* * *} p<0.0001$

(Fig. 4a-d, i). This effect reached significance only in $\mathrm{Atm}^{-1-}$ animals pre-treated with ibuprofen. Examined before the immune stimulus, $\mathrm{Atm}^{-1-}$ cerebellar astrocytes showed evidence of reduced activation as assessed by GFAP immunostaining (Fig. 4j). LPS was able to activate astrocytes in the $\mathrm{Atm}^{-1-}$ mutant cerebellum ( $[F(1$, $10)=21.67, p<0.0001]$, post hoc test: $p<0.001$ ) but not in $\mathrm{Atm}^{+/+}$animals, consistent with our previous work [24]. Even in $\mathrm{Atm}^{-1-}$ mutants, however, ibuprofen failed to reduce the astrocytic response to LPS (Fig. $4 \mathrm{e}-\mathrm{h}, \mathrm{j}$ ).
In chronic inflammatory situations lasting days, rather than hours, TNF $\alpha$ exposure has a neuroprotective role while chronic IL1 $\beta$ stimulates neurodegeneration in $\mathrm{Atm}^{-1-}$ cerebellum [25]. To determine the effects of ibuprofen treatment on these two cytokines, ELISA was performed on whole cerebellar lysates. LPS and ATM deficiency alone each showed a trend towards reduced TNF $\alpha$ in the cerebellum (Fig. 4k). A decrease in ATM-deficient cells would be consistent with our previous observations and could partially explain how 

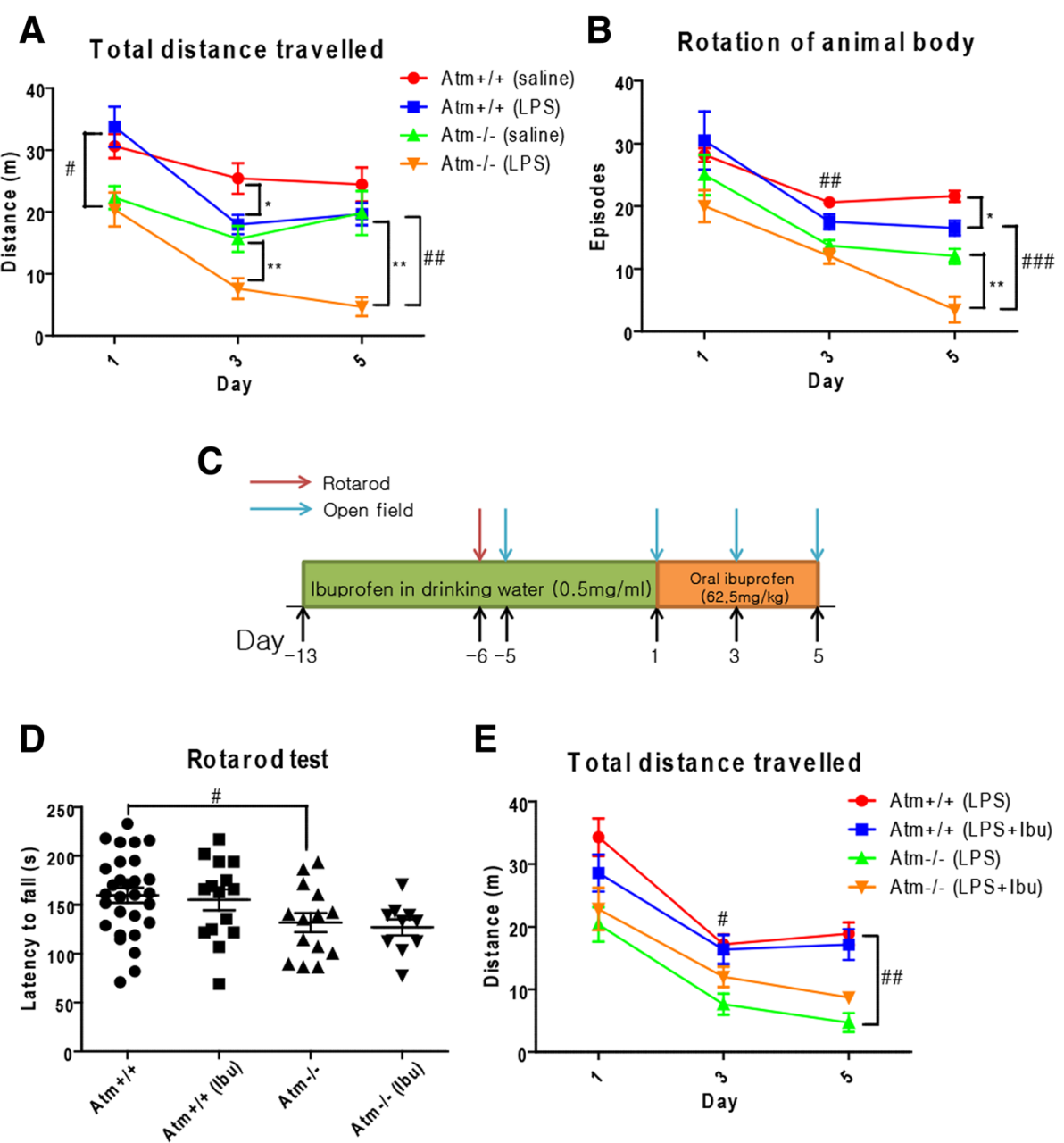

Fig. 3 Rotarod and open field test on $\mathrm{Atm}^{+/+}$and $\mathrm{Atm}^{-/-}$animals with 2-week ibuprofen administration followed by 4-day LPS injection. Atm ${ }^{-/-}$ animal traveled less distance (A) on day 1 before LPS administration. After LPS injection, both genotypes showed a significant loss of motor activity as measured by distance traveled (a) and rotation (b) on day 3 although some recovery was noted at day $5 . n=6-10$ for each group. $\mathbf{c}$ Experimental timeline for ibuprofen experiment. $\mathbf{d}$ ATM deficiency significantly reduced rotarod performance of Atm ${ }^{-1-}$ animal and ibuprofen failed to improve it. e Similar results were observed in open field tests; ibuprofen failed to improve reduced motor activities in LPS injected Atm ${ }^{-\prime}$ - animals. $n=8-11$ for each group. Two-way ANOVA was used for analyzing differences in genotype and ibuprofen treatment within an individual day. ${ }^{*} p<0.05,{ }^{* *} p<0.01$ between saline and LPS groups within the same genotype; \# $p<0.05, \# \# p<0.01$, \#\#\# $p<0.001$ between $\mathrm{Atm}^{+/+}$and $\mathrm{Atm}^{-/-}$groups with the same treatment

inflammation and ATM deficiency accelerate cerebellar damage [24]. We note that the ibuprofen pretreatment regimen failed to change even the trend in TNFa levels in both $\mathrm{Atm}^{+/+}$and $\mathrm{Atm}^{-/-}$cerebella (Fig. 4k).

Recent studies have demonstrated that peripheral immune cells also contribute to neurodegeneration in several CNS disorders [49-52]. This led us to look for infiltration of proliferating monocytes using CD45 immunohistochemistry. LPS significantly increased monocyte infiltration (Additional file 3: Figure S3A, C, E, G) in the cerebellum from both genotypes. The expression of $Y m 1$ and Trem2, two genes associated with the inhibition of inflammation and restoration of homeostasis [53, 54], were upregulated in both genotypes after LPS challenge (Trem2: $\mathrm{Atm}^{+/+}$:
$[F(1,8)=118.67, p<0.0001]$, post hoc test: $p<0.001 ; \mathrm{Atm}^{-1}$ $-:[F(1,8)=230.22, p<0.0001]$, post hoc test: $p<0.001)$ $\left(Y m 1:\left[\mathrm{Atm}^{+/+}: F(1,8)=9.44, p=0.0153\right]\right.$, post hoc test: $p<0.05 ;$ Atm $^{-/-}:[F(1,8)=8.97, p=0.0172]$, post hoc test: $p<0.05)$ ) (Additional file 2: Figure S2I and J). Ibuprofen treatment suppressed the LPS-induced monocyte infiltration and further upregulated Trem2 expression in the remaining CNS monocytes in $\mathrm{Atm}^{-1-}$ cerebellum $([F(1,8)=23.98, p=0.0012]$, post hoc test: $p<0.001)$ (Additional file 2: Figure S2C, D, G, H, J), suggesting a possible mechanism for the anti-inflammatory effect of ibuprofen in neurodegenerative disease.

Immunohistochemistry was performed to assess the anti-oxidative effect of ibuprofen. As shown in Fig. 5a, c, 


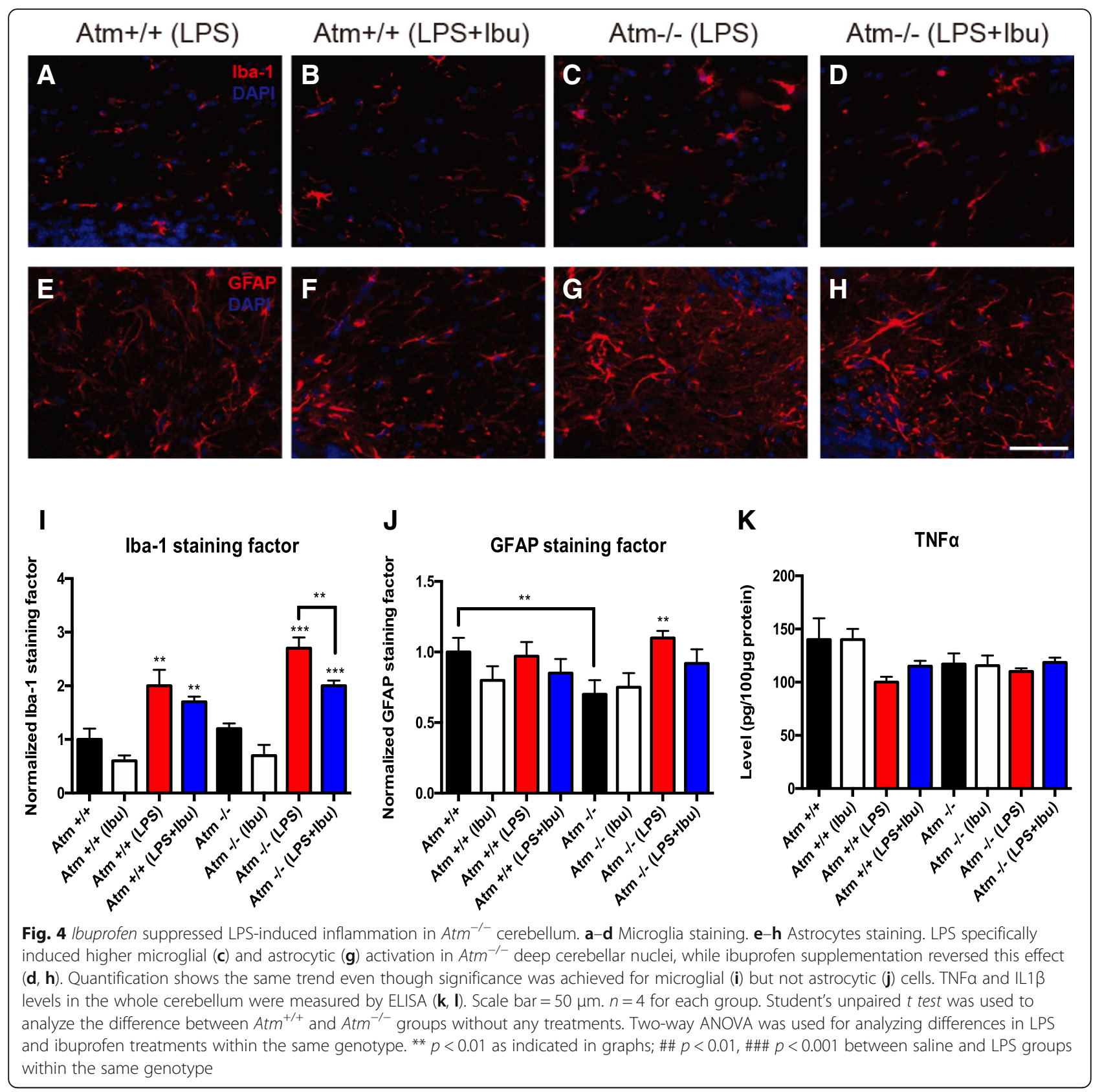

$\mathrm{Atm}^{-1-}$ cells contain higher levels of DNA oxidation as measured by 8-Oxo-2'-deoxyguanosine (8-oxo-dG), and LPS administration drives up both the total 8-oxo-dG signal intensity as well as the percentage of 8-oxo-dG positive neurons in both wildtype and $\mathrm{Atm}^{-1-}$ mice (Fig. 5a, c, e). Interestingly, not only did the total intensity of 8-oxo-dG increase in the LPS treated mice but also its nuclear localization. The nature of the cytoplasmic signal is not clear, but the enhanced levels of oxidized DNA in the cell nucleus is further evidence of the significant oxidative stress in the cells experience in these conditions and may help explain the appearance of neuronal cell cycle reentry [55] (Fig. 5a, b, d). Ibuprofen was able to blunt the LPS-induced DNA oxidation in both wildtype and ATM-deficient mice, suggesting its neuroprotective effects might be due to its function as an antioxidant. The in vivo effect was incomplete, however, as the rescue was only partial (Fig. 5). Our in vitro analysis confirmed the anti-oxidative effect of ibuprofen (Additional file 2: Figure S2O). LM treatment dramatically increased the intensity of 8-oxo-dG in cultured neurons while MM had little effect. Pre-incubation with ibuprofen significantly reduced the oxidative stress induced by LM in neuronal culture. Thus, ibuprofen alleviates the inflammatory stress caused by an LPS challenge and further 


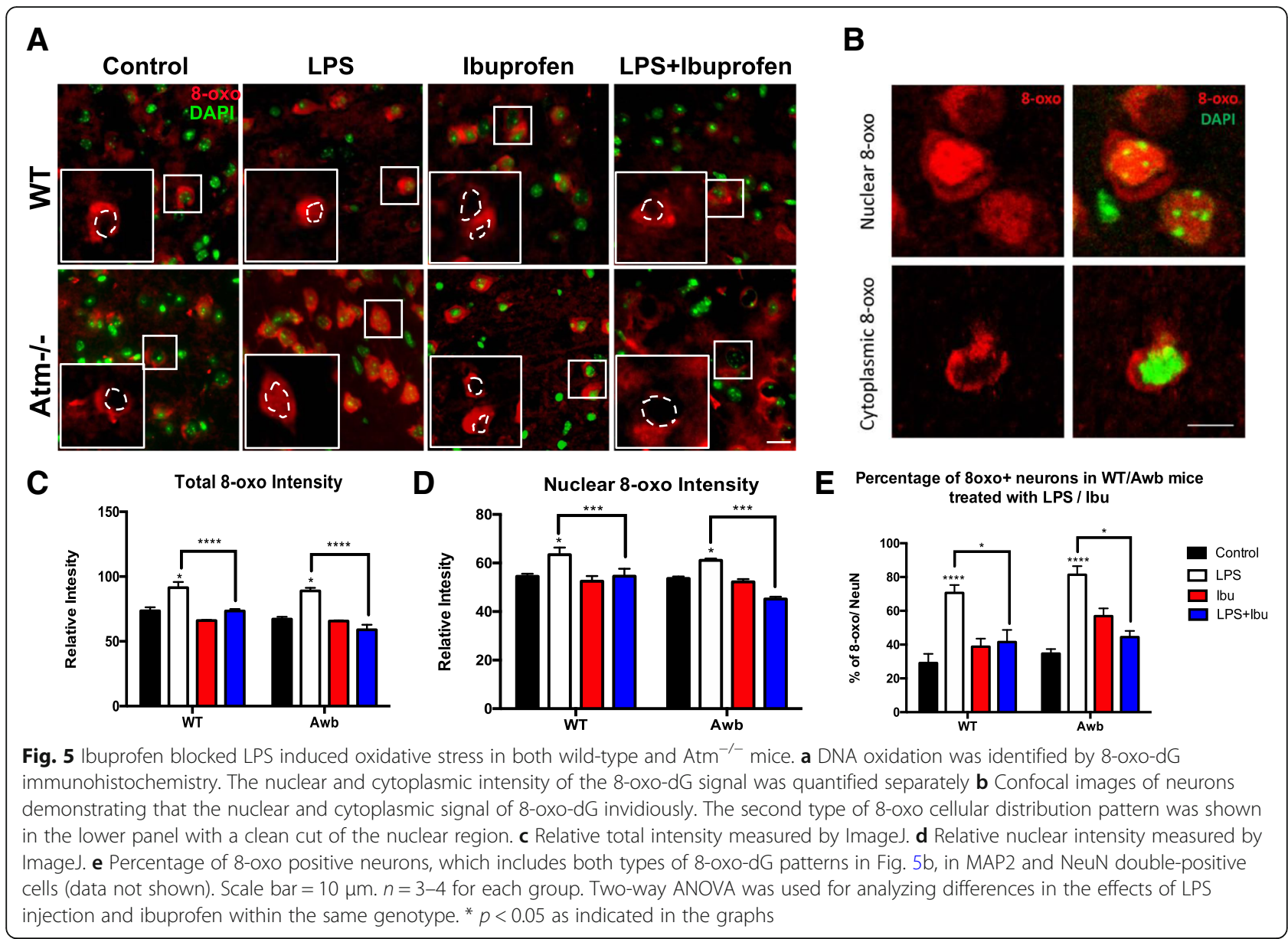

mitigates the neuronal cell loss in both wild-type and $\mathrm{Atm}^{-/-}$mice.

\section{Ibuprofen reduces cellular pathology in $\mathrm{Atm}^{-/-}$ cerebellum}

To monitor the neuropathological correlates of these changes, $10 \mu \mathrm{m}$ brain sections were immunoassayed with markers of cell cycle, DNA damage, and epigenetic and oxidative stress. Two-way ANOVA analysis revealed the main effects of LPS treatment on cyclin A $\left(\mathrm{Atm}^{+/+}\right.$: $[F(1,23)=28.49, p<0.0001]), \gamma-\mathrm{H} 2 \mathrm{AX}\left(\mathrm{Atm}^{+/+}:[F(1,23)\right.$ $=60.97, p<0.0001]$, Atm $\left.^{-1-}:[F(1,17)=8.86, p=0.0089]\right)$ and HDAC4 $\left(\mathrm{Atm}^{+/+}:[F(1,23)=15.68, p=0.0006], \mathrm{Atm}^{-\prime}\right.$ $\left.{ }^{-}:[F(1,17)=8.49, p=0.0097]\right)$, and of ibuprofen treatment on cyclin A $\left(\mathrm{Atm}^{-1-}:[F(1,17)=6.04, p=0.0251]\right)$, $\gamma$-H2AX $\left(\mathrm{Atm}^{-1-}:[F(1,17)=6.69, \quad p=0.0198]\right)$, and HDAC4 $\left(\mathrm{Atm}^{-1-}:[F(1,17)=11.68, p=0.0033]\right)$. Consistent with our previous data [24], at baseline, $\mathrm{Atm}^{-/-}$ PCs had significantly higher neuronal cell cycle events $(p<0.05)$ (Fig. 6m), DNA damage $(p<0.01)$ (Fig. 6n), and nuclear localization of HDAC4 $(p<0.001)$ (Fig. 6o) than $\mathrm{Atm}^{+/+}$PCs. Unfortunately, ibuprofen had no significant therapeutic effect on these three established phenotypes. As reported, LPS-induced immune challenge increased the three markers in both $\mathrm{Atm}^{+/+}$and mutant PCs [24] (Fig. 6m-o). Unlike the unstimulated mice, however, if given before the LPS treatment, ibuprofen significantly blunted the increase in three markers. Post hoc analysis showed that ibuprofen significantly reduced cyclin A $(p<0.001), \gamma-\mathrm{H} 2 \mathrm{AX}(p<0.01)$, and nuclear HDAC4 $(p<0.001)$ in $\mathrm{Atm}^{-/-}$Purkinje cells after LPS administration (Fig. $6 \mathrm{~m}-0$ ). These results indicate that ibuprofen counteracts the negative synergy between the Atm genotype and the neuroinflammatory environment, reducing the vulnerability of $\mathrm{Atm}^{-/-}$Purkinje cells to LPS-induced damage.

\section{Ibuprofen suppresses LPS- and ATM deficiency-induced p38 phosphorylation}

LPS-induced neuronal damage is correlated with the activation of the MAPK, Akt, and NFKB pathways [25]. This led us to ask whether ibuprofen was able to suppress these changes. Whole cerebellar lysates were prepared, followed by Western blots with antisera to proteins involved in above three pathways. LPS, with or without ibuprofen, stimulated no obvious activation 


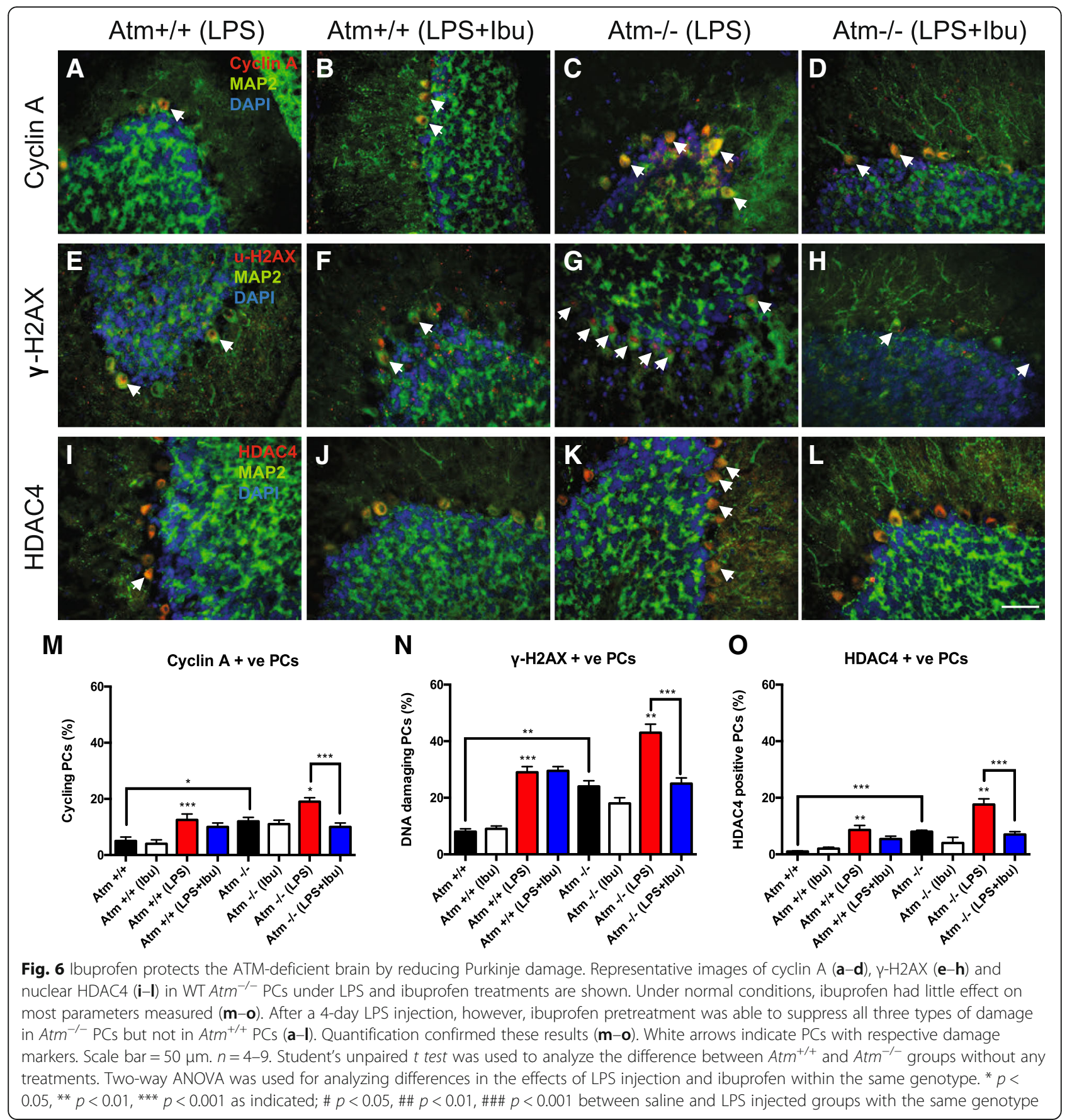

(phosphorylation) of ERK or Akt pathways in whole cerebella extracts of either genotype (Additional file 4: Figure S4). As PCs represent less than 1\% of the total number of cells in the cerebellum, whole cell lysates might obscure differences that were taking place only in this one cell type. We therefore turned to immunohistochemistry to investigate the levels of phospho-p38 specifically in PCs. In this way, we found that both ATM deficiency and LPS injection in wild-type mice induced p38 activation in PCs (Fig. 7c, e and Additional file 5:
Figure S5). In $\mathrm{Atm}^{-/-}$mice, LPS injection did not show any combinatorial effect. Unexpectedly, p38 induction in $\mathrm{Atm}^{-1-}$ animals trended lower after LPS injection (Fig. $7 \mathrm{~g}$ and Additional file 5: Figure S5). Two-way ANOVA revealed significant differences in LPS $\left(\mathrm{Atm}^{+/+}:[F(1,8)=\right.$ 66.27, $p<0.0001]$, Atm $\left.^{-1-}:[F(1,8)=13.20, p=0.0068]\right)$ and ibuprofen treatments $\left(\mathrm{Atm}^{+/+}:[F(1,8)=44.00, p=0.0002]\right.$, $\left.\mathrm{Atm}^{-1-}:[F(1,8)=296.98, p<0.0001]\right)$ in both genotypes. Ibuprofen was able to block the LPS-induced increase in p38 phosphorylation and surprisingly was equally effective 


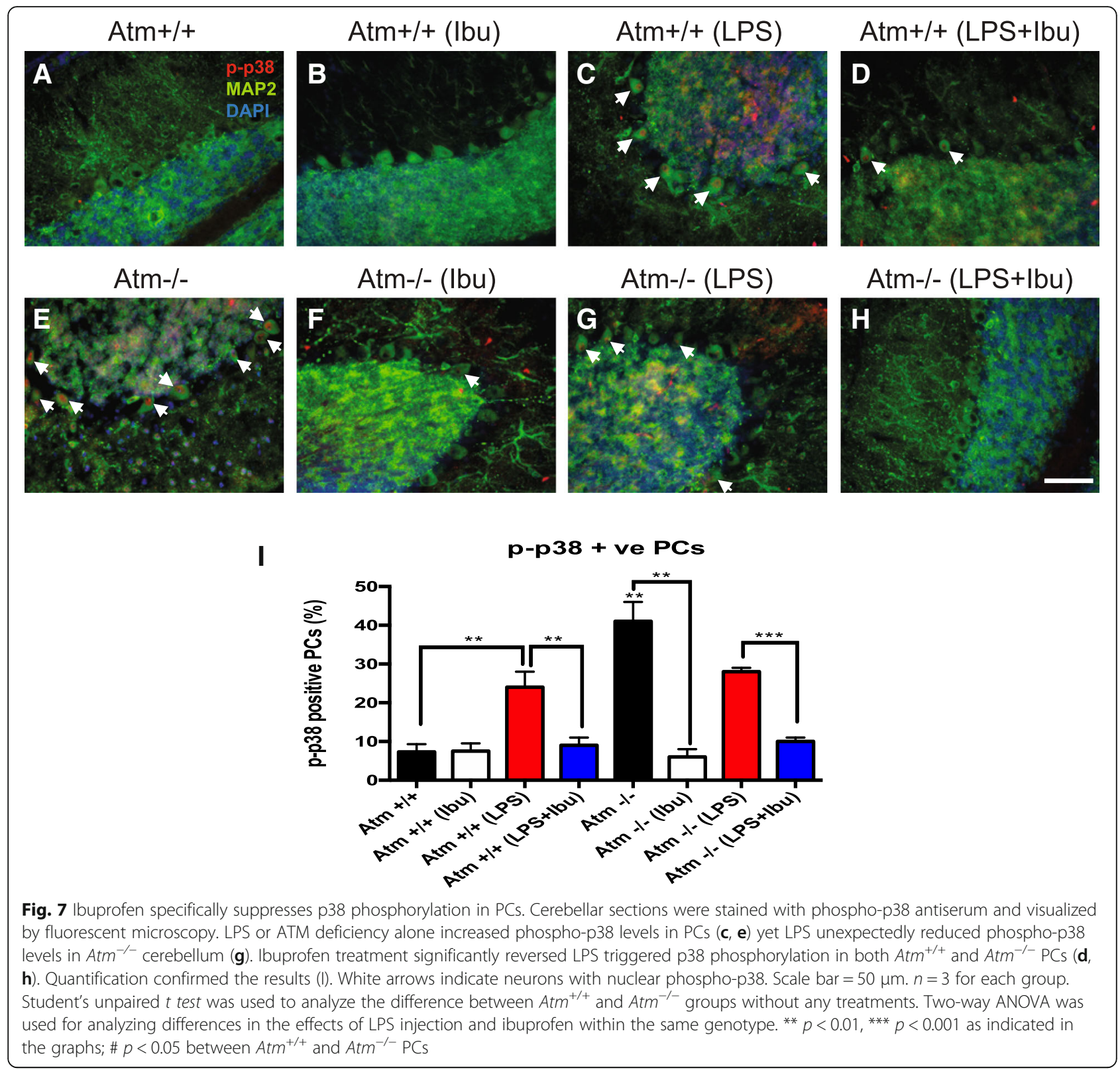

at reducing the ATM-dependent activation of p38 in PCs (Fig. 7 b, d, f, h and Additional file 5: Figure S5). Quantification of the immunohistochemistry confirmed these results $\left(\right.$ Atm $^{+/+}: p<0.01 ;$ Atm $\left.^{-/-}: p<0.001\right)$ (Fig. 7i). These data thus suggest that ibuprofen mainly delays the A-T progression at least in part through the suppression of p38 activation in the cerebellum.

\section{Early ibuprofen treatment delays the initiation of A-T symptoms}

All of the above studies were performed in adult $\mathrm{Atm}^{-/-}$ mice with established pathology and defined motor symptoms. We note that even at this relatively late disease stage, ibuprofen is still beneficial. We next asked whether ibuprofen might perhaps have more significant protective effects if it were applied before the first appearance of symptoms. To test this, wild-type and $\mathrm{Atm}^{-}$ - mice were administrated ibuprofen orally for 2 weeks starting at age P10, an age before the earliest signs of PC distress are apparent [56]. After 2 weeks of treatment, the animals were killed by perfusion and their brains embedded in OCT for sectioning on a cryostat. Immunostaining was performed to access the level of neuronal damage. We found significant effects of genotype (PCNA: $[F(1,14)=54.19, p<0.0001]$; cyclin A: $[F(1,14)$ $=21.23, p=0.0004]$ ) and ibuprofen treatment (cyclin A: $[F(1,14)=10.82, p=0.0054])$ in the damage markers by two-way ANOVA. Post hoc test revealed that ibuprofen 
blocked the developmental appearance of ectopic cell cycling in the $\mathrm{Atm}^{-/-}$Purkinje cells (PCNA: $p<0.01$, cyclin A: $p<0.001-$ Fig. 8a, b). By contrast, DNA damage was induced in $\mathrm{Atm}^{-1-}$ Purkinje cells $([F(1,14)$ $=26.64, p=0.0001$ ], post hoc test: $p<0.01)$ but not significantly reduced under ibuprofen treatment (Fig. 8c). No change was found in HDAC4 localization (Fig. 8d). The same phenomenon was observed in $\mathrm{Atm}^{-/-}$neocortical neurons where we found a significant effect of ibuprofen in suppressing these damage markers under post hoc analysis (PCNA: $p<0.05$; cyclin A: $p<0.05$; $\gamma$-H2AX: $p<0.01-$ Fig. $8 \mathrm{e}-\mathrm{g}$ ). In wild-type brains, ibuprofen had no effect, perhaps because there was little to no signal to begin with, (Fig. 8a-h). Of note, we found that HDAC4 translocation to the nucleus was not obvious in 1-month-old $\mathrm{Atm}^{-/-}$animals. This suggests that, although it will develop as an important phenotype by 3 months of age (Fig. 6 plus reference [57]), it is less prominent in the developing $\mathrm{Atm}^{-/-}$brain.

\section{Discussion}

The immune and nervous systems interact extensively-with each affecting the behavior of the other for both good and bad. ATM deficiency, in humans and in mice, illustrates this point well. By morphological criteria, brain microglial cells are activated in humans, $\mathrm{Atm}^{-1-}$ mice, and a recently developed $\mathrm{Atm}^{-1-}$ rat model and display a more severe pro-inflammatory syndrome $[58,59]$. The innate immune system in ATM deficiency also appears to be hypersensitive to exogenous challenges [60, 61]. The exaggerated loss of motor function after LPS treatment of $\mathrm{Atm}^{-1-}$ mice and the correlated changes seen in our immunohistochemistry findings suggest that this hypersensitivity leads to neuronal cell stress as seen in the accumulation of neuronal cell cycle events, evidence of DNA damage, and the nuclear localization of HDAC4 in Purkinje neurons.

Recent developments make it likely that the involvement of ATM in this chronic activation of the immune system is due in part to the presence of DNA damage. Accumulated cytoplasmic DNA, presumably enhanced after DNA damage, can trigger an innate immune response [58, 59, 62, 63]. .In our model, increased oxidative stress, produced during the immune challenge, induces DNA damage in the nucleus. In the absence of ATM function, DNA repair is compromised which leads to DNA fragments accumulating in the cytoplasm. This would then serve as a "danger" signal that would initiate an immune response via the viral DNA sensor STING or other factors [59]. Thus, an immune challenge exacerbates the oxidative stress in a cell leading to more DNA damage and an increased cellular reliance on ATM function.

\section{Anti-oxidative effect as the main protective mechanism}

The presence of oxidative stress in conditions of ATM deficiency is clear and our data suggest that it is in fact the ability of ibuprofen to function as an anti-oxidant that serves as the major source of its ability to blunt the effects of an immune challenge both in vivo and in vitro. Previous findings and our own results have shown that LPS induces cytokine expression [14, 15] and triggers the release of reactive oxygen products $[16,17]$ in primary cultured microglia, human THP-1 cells, and macrophages [34]. As the conditioned medium from LPS-stimulated microglia (LM) contains a "cocktail" of cytokines and ROS, it is likely that these works together to cause neuronal damage. As expected, LPS increased the neurotoxic effect of the medium from unstimulated microglia (MM) and ibuprofen was able to rescue this damage. Similar to our findings (Fig. 2 and Additional file 1: Figure S1), several groups have shown that ibuprofen fails to significantly inhibit inflammation in the cultured innate immune cells and in the monocyte-neuronal co-culture system with acute inflammation [64, 65]. Indeed, in one case study of a patient with acute endotoxemia, ibuprofen was actually found to cause significant increases of circulating pro-inflammatory TNF- $\alpha$ and IL-6 [66]. .Importantly, in a series of related observations, long-term ibuprofen treatment and the resulting inhibition of COX activity enhanced rather than suppressed the inflammatory phenotype of macrophages [47]. As a result, the anti-inflammatory features of ibuprofen are affected by the dose, duration of incubation, and the cell types used for the experiment, an important feature to keep in mind when clinical studies are designed.

Evidence for the role of oxidative damage in the action of ibuprofen can also be found in the response of neuronal cultures challenged by exposure to medium from LPS-stimulated cells (LM). Ibuprofen reduced the number of neurons showing signs of oxidative stress and cellular damage if it was administered directly to the neurons before they were exposed to LM (Figs. 1 and 2 and Additional file 2: Figure S2). This neuroprotective effect may be due in part to the anti-oxidative properties of ibuprofen (Fig. 5 and Additional file 2: Figure S2) as described previously [34]. Oxidative stress is believed to induce neuronal apoptosis and/or necrosis-like cell death which does not involve caspase activation [67]. The data in Fig. 2 shows that LM enhances the PI signal of our cell death marker indicating the neuronal deaths are most likely necrosis-like events. Also, ibuprofen pretreatment is able to reduce PI signal in LM treated neurons, suggesting a reduction in intracellular superoxide anion production from neurons and the anti-oxidative feature of ibuprofen [67]. The previous study showed that, even as a DNA damage repair protein, ATM can also be activated by intracellular oxidative stress. Normal 

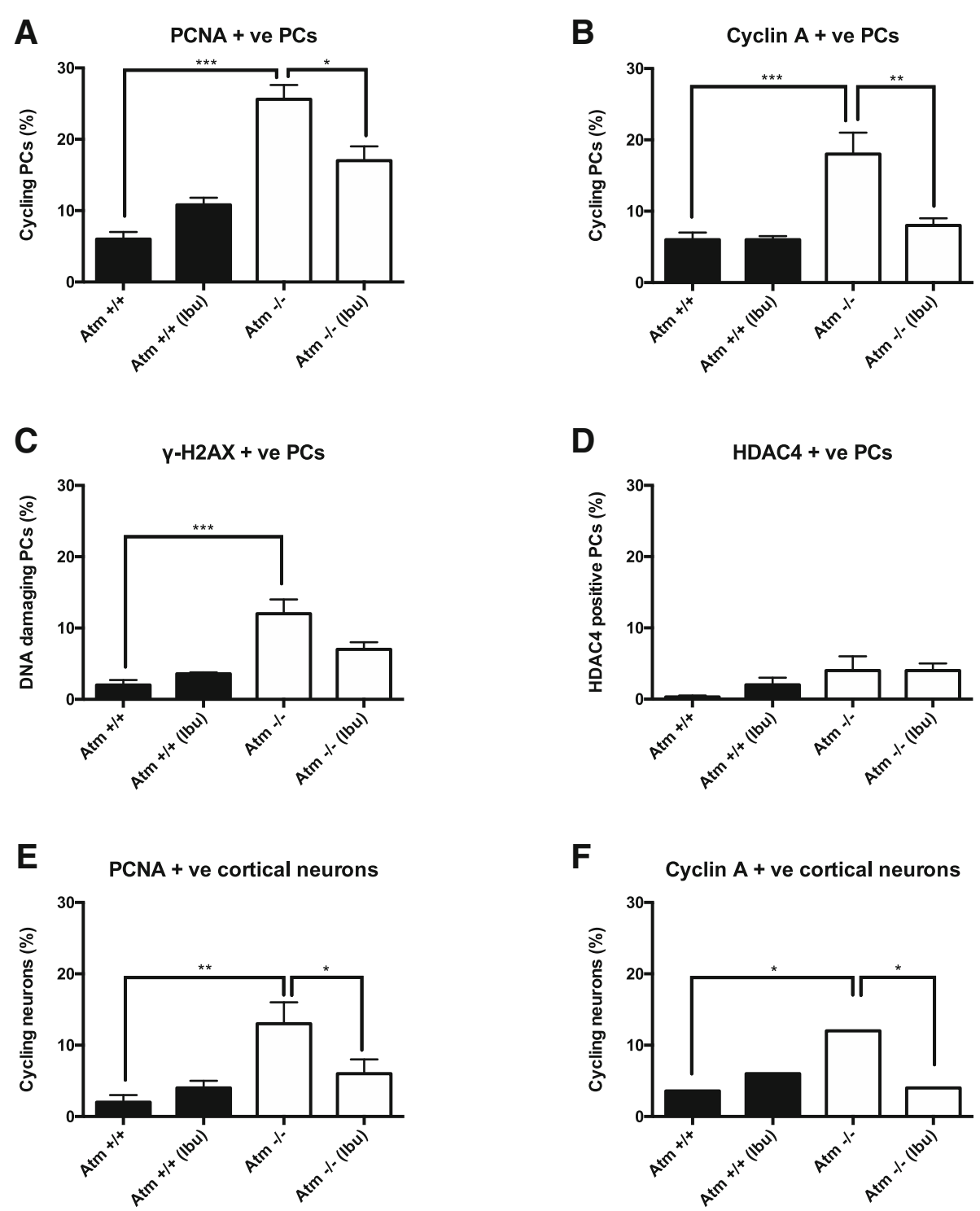

$\mathbf{F}$

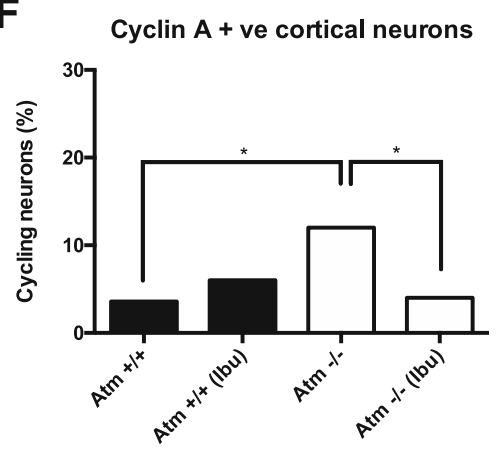

G

H
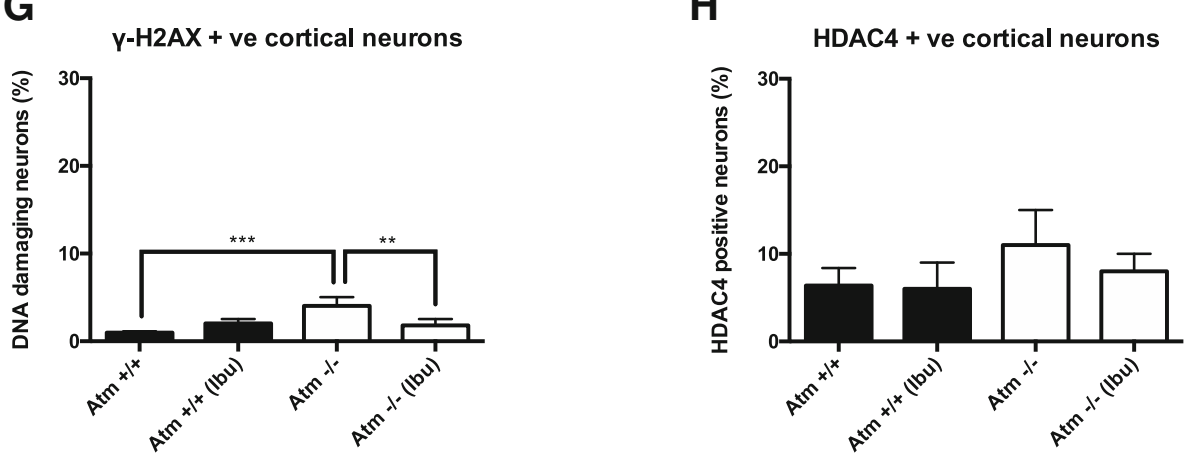

Fig. 8 Ibuprofen reduces early cellular damage in $\mathrm{Atm}^{-1-}$ animals. Ibuprofen prevented cell cycle reentry (a-b) and DNA damage (c) in Atm ${ }^{-1-}$

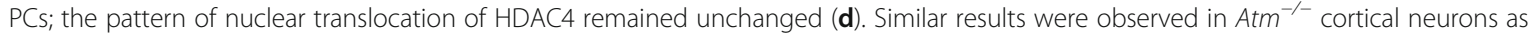
measured by neuronal cell cycle activity (e-f), DNA damage (g) and nuclear HDAC4 expression (h). Ibuprofen alone did not induce any changes in $\mathrm{Atm}^{+/+}$cerebellum (a-d) or cortex (e-h). $n=4-5$ for each group. Two-way ANOVA was used for analyzing differences in genotype and ibuprofen treatment. ${ }^{*} p<0.05,{ }^{* *} p<0.01,{ }^{* *} p<0.001$ 
function and activity of ATM is significantly crucial for keeping the redox balance in the cytoplasm [68, 69]. During the LPS challenge, immune cells like microglia and THP-1 cells produce substances that serve as reactive oxidants and greatly contribute to the neuronal cell damage. Ibuprofen pretreatment relieves the oxidative stress in the microenvironment and contributes to the homeostasis in the central nerves system. These data are consistent with work from Wilkinson et al. that ibuprofen can directly protect neurons from oxidative stress [34].

\section{Ibuprofen can prevent but not reverse the progression of A-T symptoms}

The question that naturally arises from these findings is whether reducing this innate immune system hypersensitivity might have therapeutically beneficial effects. We previously showed in a series of studies in mouse models of Alzheimer's disease (AD) that increasing inflammation with a broad-spectrum LPS challenge advances the timing of AD symptoms while oral NSAIDs (ibuprofen or naproxen) retard it [33]. We were encouraged by these earlier findings to test whether a regimen of NSAID administration might also prove beneficial in a mouse model of A-T. As ibuprofen can directly block LPS-induced dendritic loss and reduce spine density [51], we tested whether it might also suppress inflammation-induced A-T symptoms either in vitro or in vivo.

Based on our earlier work in mouse models of Alzheimer's disease (AD) [33], we hypothesized that ibuprofen might prevent the emergence of A-T symptoms. This hypothesis has largely proved correct. Indeed, the similarities in the response to ibuprofen of the A-T and $\mathrm{AD}$ models are striking, despite the fact that they are two very different neurodegenerative diseases. In parallel with the findings in the $\mathrm{AD}$ mice, neither the cellular nor the behavioral symptoms of adult A-T animals are reversed with NSAID therapy. PC stress fails to improve following ibuprofen treatment, and there is no obvious improvement in behavioral test performance-either coordination as measured on the rotarod or open field behavior.

Yet, ibuprofen can blunt the effects of additional immune/oxidative challenges. Similar to AD animals with ibuprofen supplementation [33, 49, 52, 70, 71], mature A-T animals treated with ibuprofen are less vulnerable to LPS-induced motor dysfunction; more modest benefits were observed for LPS-treated $\mathrm{Atm}^{+/+}$(Fig. 4c-e). These results indicate that ibuprofen can suppress new or accelerated symptom appearance during an inflammatory challenge, but once symptoms are established, it cannot reverse the previous damage. This is exactly the situation found when the impact of ibuprofen is tested on the chronic inflammation found in $\mathrm{AD}$ model mice.
It is interesting to note that while ibuprofen does not reverse the behavioral symptoms of mature $\mathrm{Atm}^{-/-}$cerebellum, it nonetheless reduces the microglial morphological response (Fig. 4), tissue oxidation (Fig. 5), and several types of PC damage (Fig. 6). These results are consistent with other groups who found that neuronal abnormalities could be reversed by ibuprofen through anti-inflammatory and anti-oxidative effects [26-28, 34] and is in line with our tissue culture findings showing that ibuprofen applied directly to neurons blocks the effects of LM; but if applied to the microglia themselves, it has little effect. The anti-inflammatory component of the effect of ibuprofen on cerebellar Purkinje cells should be viewed in the context, cerebellar microglia have different immune responses from those in cerebral cortex and hippocampus [72], and in this difference may lie the regional variability that accompanies the clinical picture in $\mathrm{AD}$ as well as $\mathrm{A}-\mathrm{T}$. Thus, A-T has its most dramatic effects in the cerebellum, and neuronal damage in $\mathrm{AD}$ is most obvious in entorhinal cortex and hippocampus. Further support for this concept comes from bioinformatics reports showing that cerebellar microglial cells have different clusters of expressed genes compared to cortical microglia. The classical (LPS) and alternative (interleukin 4) activated pathways in cerebellar microglia are also different from those observed in other brain regions [73]. An additional contributor to this regional variation might be the fact that the cerebellum has the smallest numbers of microglia and astrocytes in vivo [74].

\section{Early ibuprofen treatment reverses the development of A- T symptoms}

More dramatic than the protection offered against new LPS-induced symptoms in adult animals is our finding that ibuprofen prevents the development of symptoms during the natural history of the Atm ${ }^{\text {tm } 1 A w b}$ mouse A-T model. Normally, cellular symptoms such as elevated cell cycle events appear between postnatal day 10 and 20 in the mouse [56]. But beginning at P10, 2 weeks of oral ibuprofen administration totally blocked the appearance of disease symptoms in both cerebellum and cortex. These data have potentially important clinical relevance as they suggest that ibuprofen might block or retard the development A-T pathology in pre-symptomatic children. The data lead to the hypothesis that under normal conditions, established disease symptoms cannot be improved by NSAID treatment, but before they appear or worsen, an individual suffering with ATM deficiency might benefit from this simple therapeutic approach. At the very least, as we have suggested previously [24], aggressive anti-inflammatory treatment during the course of A-T could have significant benefit. More speculative for the moment, but potentially more exciting, our experiments with the pre-symptomatic ATM-deficient 
mice suggest that early intervention in children might postpone the onset of disease symptoms for an unknown period of time. Taken together with our current findings, the data argue that ibuprofen should be considered as a therapeutic agent in preventing the initiation of A-T.

\section{Conclusions}

The current study shows that the severity of the symptoms of A-T is closely correlated with the level of neuroinflammation and oxidative stress in the CNS. We find that the common NSAID, ibuprofen, is able to partially prevent the exacerbated behavioral deficits induced by an acute immune system challenge and can suppress several cellular deficits observed in LPS-stressed $\mathrm{Atm}^{-1-}$ mice. The data suggest that the actions of ibuprofen include both anti-inflammatory and anti-oxidative effects. Based on our findings, we propose that early ibuprofen treatment may help to prevent or delay the progression of A-T in human patients.

\section{Additional files}

Additional file 1: Figure S1. Gene expression profile of microglia and THP-1 cells under LPS challenge and ibuprofen pretreatment. THP-1 cells were treated with ibuprofen $(0,3,10,40,80,200 \mu \mathrm{M})$ for $6 \mathrm{~h}$ and then challenged with LPS for $48 \mathrm{~h}$. Gene expression of TNFa (D), ILIB (E), IL6 (F), COX2 $(\mathrm{G})$ and $/ \mathrm{L} 8(\mathrm{H})$, SOCS3 (I), CD45 (J), CD11b (K), P50 (L) and P65 (M) was assessed by PCR. (A). Microglia were treated with LPS for $48 \mathrm{~h}$ and then assessed by qPCR. (B). qPCR analysis of microglia treated with LPS and ibuprofen. $N=3-4$ for each group. Student's unpaired $t$ test was used to analyze the difference between vehicle and LPS treated groups. Twoway ANOVA was used for analyzing differences in LPS and ibuprofen treatments. ${ }^{*}, p<0.05,{ }^{* *}, p<0.01,{ }^{* *}, p<0.001$ between LPS group and control group without ibuprofen pretreatment. (PDF $208 \mathrm{~kb}$ )

Additional file 2: Figure S2. (A-N). Ibuprofen pretreatment of THP-1 cells partially rescued LPS-induced neuronal damage. $(A-H)$. Conditioned medium from ibuprofen pretreated THP-1 cells was harvested and applied to DIV14 cultured neurons. Ibuprofen has positive effect on neuronal survival and partially attenuated the appearance of CCEs as measured either by EdU or Ki67. $n=3$ for each group. Two-way ANOVA was used for analyzing ibuprofen effect within each TM/LM treatment. (O). Oxidative stress in the cultured neuron was measured by 8oxoguanine. LM from primary cultured microglia was then applied to neuronal culture. It significant increase the level of 8-oxoguanine while ibuprofen alleviate the oxidative stress in the culture system. Scale bar $=50 \mu \mathrm{m} . n=3$ for each group (PDF $3439 \mathrm{~kb}$ )

Additional file 3: Figure S3. Ibuprofen stimulated formation of tissuerepairing monocytes in cerebellum. LPS stimulated monocyte infiltration while ibuprofen suppressed this invasion $(C, D, G, H)$. Although ibuprofen failed to further stimulate $Y m 1$ expression (I), it specifically induced Trem2 expression in monocytes infiltrating the $\mathrm{Atm}^{-1-}$ cerebellum (J). Scale bar $=50 \mu \mathrm{m} . n=3$ for each group. Two-way ANOVA was used for analyzing differences in LPS and ibuprofen treatments within the same genotype. $*_{* *}^{*}, p<0.001$ between groups with and without ibuprofen treatment in LPS injected Atm $^{-1-}$ cerebellum; \#, $p<0.05$, \#\#, $p<0.01$, \#\#, $p<0.001$ groups with and without LPS treatment in the same genotype. (TIF $2427 \mathrm{~kb}$ )

Additional file 4: Figure S4. Akt, MAPK and NFkB pathways were investigated in cerebellar lysates by immunoblotting (A, B). Ibuprofen failed to affect ERK, JNK, Akt or p65 phosphorylation during an LPS challenge (C, E, F, G and data not shown). It reduced p38 phosphorylation only in $\mathrm{Atm}^{+/+}$cerebellum (D). $n=4$ for each group.
Two-way ANOVA was used for statistical analysis. ${ }^{*}, p<0.05$ compared to $\mathrm{Atm}^{+/+}$saline group. (PDF $771 \mathrm{~kb}$ )

Additional file 5: Figure S5. Ibuprofen specifically suppresses p38 phosphorylation in PCs. Cerebellar sections were stained with phospho-p38 antiserum and visualized by fluorescent microscopy. LPS or ATM deficiency alone increased phospho-p38 levels in PCS (C, E) yet LPS unexpectedly reduced phospho-p38 levels in Atm $^{-1-}$ cerebellum (G). Ibuprofen treatment significantly reversed LPS triggered p38 phosphorylation in both $\mathrm{Atm}^{+/+}$and $\mathrm{Atm}^{-/-}$PCs (D, H). (PDF $\left.3474 \mathrm{~kb}\right)$

\section{Abbreviations}

AD: Alzheimer's disease; A-T: Ataxia telangiectasia; ATM: Ataxia telangiectasiamutated; CCE: Cell cycle event; CNS: Central nervous system; DCN: Deep cerebellar nuclei; LM: LPS-stimulated microglia conditioned medium; LM: LPS-stimulated THP-1 cell conditioned medium; LPS: Lipopolysaccharide; MM: Unstimulated microglia conditioned medium; NSAID: Non-steroidal antiinflammatory drug; PC: Purkinje cell; ROS: Reactive oxygen species;

TM: Unstimulated THP-1 cell conditioned medium

\section{Acknowledgements}

We express our sincere thanks to the technicians in core animal facility from Hong Kong University of Science and Technology for the routine management in mouse colonies. We also gratefully thank Prof. Nancy Ip for providing the THP-1 cell line used in the current study.

\section{Funding}

This work was supported by the National Key Basic Research Program of China (2013CB530900), The Research Grants Council, HKSAR (HKUST GRF660813 and GRF 16101315), the BrightFocus Foundation, A-T Children's Project, and by the US NIH (NS71022). The support of The Hong Kong University of Science and Technology (R9321) is also gratefully acknowledged.

\section{Availability of data and materials}

The datasets used and analyzed during the current study are available from the corresponding author on reasonable request.

All data generated or analyzed during this study are included in this published article and its supplementary information files.

\section{Authors' contributions}

$\mathrm{CWH}, \mathrm{XS}$, and $\mathrm{KH}$ conceived and designed the experiments. CWH XS, XTS, and FLM performed the experiments. CWH, XS, XTS, FLM, and KH analyzed the data. $\mathrm{CWH}, \mathrm{XS}, \mathrm{XTS}$, and $\mathrm{KH}$ wrote the paper. All authors read and approved the final manuscript.

\section{Authors' information}

Information for all the co-authors is listed in the title page.

\section{Ethics approval and consent to participate}

Not applicable

\section{Consent for publication}

All authors consent for the publication of this study.

\section{Competing interests}

The authors declare that they have no competing interests.

\section{Publisher's Note}

Springer Nature remains neutral with regard to jurisdictional claims in published maps and institutional affiliations.

\section{Author details}

'Division of Life Science and State Key Laboratory of Molecular Neurobiology, Hong Kong University of Science and Technology, Clear Water Bay, Kowloon, Hong Kong. ${ }^{2}$ Present address: School of Biomedical Sciences, The University of Hong Kong, Pokfulam, Hong Kong. 
Received: 6 January 2018 Accepted: 18 October 2018 Published online: 06 November 2018

\section{References}

1. Lavin MF, Shiloh Y. The genetic defect in ataxia-telangiectasia. Annu Rev Immunol. 1997;15:177-202

2. Chun HH, Gatti RA. Ataxia-telangiectasia, an evolving phenotype. DNA Repair (Amst). 2004;3:1187-96.

3. Biton S, Barzilai A, Shiloh Y. The neurological phenotype of ataxiatelangiectasia: solving a persistent puzzle. DNA Repair (Amst). 2008;7:1028-38.

4. Gatti RA, Becker-Catania S, Chun HH, Sun X, Mitui M, Lai CH, Khanlou N, Babaei M, Cheng R, Clark C, et al. The pathogenesis of ataxia-telangiectasia. Learning from a Rosetta stone. Clin Rev Allergy Immunol. 2001;20:87-108.

5. Heppner FL, Ransohoff RM, Becher B. Immune attack: the role of inflammation in Alzheimer disease. Nat Rev Neurosci. 2015;16:358-72.

6. Milatovic D, Zaja-Milatovic S, Montine KS, Shie FS, Montine TJ. Neuronal oxidative damage and dendritic degeneration following activation of CD14dependent innate immune response in vivo. J Neuroinflammation. 2004;1:20.

7. Steinman L. Elaborate interactions between the immune and nervous systems. Nat Immunol. 2004;5:575-81.

8. Veres TZ, Rochlitzer S, Braun A. The role of neuro-immune cross-talk in the regulation of inflammation and remodelling in asthma. Pharmacol Ther. 2009;122:203-14

9. Matt SM, Johnson RW. Neuro-immune dysfunction during brain aging: new insights in microglial cell regulation. Curr Opin Pharmacol. 2015;26:96-101.

10. Austin PJ, Berglund AM, Siu S, Fiore NT, Gerke-Duncan MB, Ollerenshaw SL, Leigh SJ, Kunjan PA, Kang JW, Keay KA. Evidence for a distinct neuroimmune signature in rats that develop behavioural disability after nerve injury. J Neuroinflammation. 2015;12:96

11. Morris $\mathrm{G}$, et al. The neuro-immune pathophysiology of central and peripheral fatigue in systemic immune-inflammatory and neuro-immune diseases. Mol Neurobiol. 2016;53(2):1195-219.

12. Gutierrez-Fernandez F, Pinto-Gonzalez M, Gonzalez-Perez O. Neuro-immune interactions in the postnatal ventricular-subventricular zone. J Stem Cells. 2014;9:53-64.

13. Ermakov AV, Konkova MS, Kostyuk SV, Izevskaya VL. Oxidized extracellular DNA as a stress signal in human cells. Oxidative Med Cell Longev. 2013;2013:649747.

14. Schildberger A, Rossmanith E, Eichhorn T, Strassl K, Weber V. Monocytes, peripheral blood mononuclear cells, and THP-1 cells exhibit different cytokine expression patterns following stimulation with lipopolysaccharide. Mediat Inflamm. 2013;2013:697972.

15. Chanput W, Mes J, Vreeburg RA, Savelkoul HF, Wichers HJ. Transcription profiles of LPS-stimulated THP-1 monocytes and macrophages: a tool to study inflammation modulating effects of food-derived compounds. Food Funct. 2010;1:254-61.

16. Sarna LK, Wu N, Hwang SY, Siow YL, O K. Berberine inhibits NADPH oxidase mediated superoxide anion production in macrophages. Can J Physiol Pharmacol. 2010;88:369-78.

17. Zhang X, Cao J, Jiang L, Zhong L. Suppressive effects of hydroxytyrosol on oxidative stress and nuclear factor-kappaB activation in THP-1 cells. Biol Pharm Bull. 2009;32:578-82.

18. Bhatt JM, Bush A. Microbiological surveillance in lung disease in ataxia telangiectasia. Eur Respir J. 2014;43:1797-801.

19. Staples ER, McDermott EM, Reiman A, Byrd PJ, Ritchie S, Taylor AM, Davies EG. Immunodeficiency in ataxia telangiectasia is correlated strongly with the presence of two null mutations in the ataxia telangiectasia mutated gene. Clin Exp Immunol. 2008;153:214-20.

20. Menotta M, Biagiotti S, Bianchi M, Chessa L, Magnani M. Dexamethasone partially rescues ataxia telangiectasia-mutated (ATM) deficiency in ataxia telangiectasia by promoting a shortened protein variant retaining kinase activity. J Biol Chem. 2012;287:41352-63.

21. Zannolli R, Buoni S, Betti G, Salvucci S, Plebani A, Soresina A, Pietrogrande MC, Martino S, Leuzzi V, Finocchi A, et al. A randomized trial of oral betamethasone to reduce ataxia symptoms in ataxia telangiectasia. Mov Disord. 2012;27:1312-6.

22. Kuljis RO, Xu Y, Aguila MC, Baltimore D. Degeneration of neurons, synapses, and neuropil and glial activation in a murine Atm knockout model of ataxia-telangiectasia. Proc Natl Acad Sci U S A. 1997:94:12688-93.

23. Petersen AJ, Rimkus SA, Wassarman DA. ATM kinase inhibition in glial cells activates the innate immune response and causes neurodegeneration in Drosophila. Proc Natl Acad Sci U S A. 2012;109:E656-64.
24. Yang Y, Hui CW, Li J, Herrup K. The interaction of the atm genotype with inflammation and oxidative stress. PLoS One. 2014;9:e85863.

25. Hui CW, Herrup K. Individual cytokines modulate the neurological symptoms of ATM deficiency in a region specific manner $(1,2,3)$. eNeuro. 2015;2:ENEURO-0032.

26. Cakala M, Malik AR, Strosznajder JB. Inhibitor of cyclooxygenase-2 protects against amyloid beta peptide-evoked memory impairment in mice. Pharmacol Rep. 2007:59:164-72.

27. Gopez JJ, Yue H, Vasudevan R, Malik AS, Fogelsanger LN, Lewis S, Panikashvili D, Shohami E, Jansen SA, Narayan RK, Strauss KI. Cyclooxygenase-2-specific inhibitor improves functional outcomes, provides neuroprotection, and reduces inflammation in a rat model of traumatic brain injury. Neurosurgery. 2005;56:590-604.

28. Scali C, Giovannini MG, Prosperi C, Bellucci A, Pepeu G, Casamenti F. The selective cyclooxygenase-2 inhibitor rofecoxib suppresses brain inflammation and protects cholinergic neurons from excitotoxic degeneration in vivo. Neuroscience. 2003;117:909-19.

29. Vlad SC, Miller DR, Kowall NW, Felson DT. Protective effects of NSAIDs on the development of Alzheimer disease. Neurology. 2008:70:1672-7.

30. Choi JK, Carreras I, Aytan N, Jenkins-Sahlin E, Dedeoglu A, Jenkins BG. The effects of aging, housing and ibuprofen treatment on brain neurochemistry in a triple transgene Alzheimer's disease mouse model using magnetic resonance spectroscopy and imaging. Brain Res. 2014;1590:85-96.

31. Babiloni C, Frisoni GB, Del Percio C, Zanetti O, Bonomini C, Cassetta E, Pasqualetti $P$, Miniussi C, De Rosas M, Valenzano A, et al. Ibuprofen treatment modifies cortical sources of EEG rhythms in mild Alzheimer's disease. Clin Neurophysiol. 2009;120:709-18.

32. Jin DQ, Sung JY, Hwang YK, Kwon KJ, Han SH, Min SS, Han JS. Dexibuprofen $(S(+)$-isomer ibuprofen) reduces microglial activation and impairments of spatial working memory induced by chronic lipopolysaccharide infusion. Pharmacol Biochem Behav. 2008;89:404-11.

33. Varvel NH, Bhaskar K, Kounnas MZ, Wagner SL, Yang Y, Lamb BT, Herrup K. NSAIDs prevent, but do not reverse, neuronal cell cycle reentry in a mouse model of Alzheimer disease. J Clin Invest. 2009;119:3692-702.

34. Wilkinson BL, Cramer PE, Varvel NH, Reed-Geaghan E, Jiang Q, Szabo A, Herrup K, Lamb BT, Landreth GE. Ibuprofen attenuates oxidative damage through NOX2 inhibition in Alzheimer's disease. Neurobiol Aging. 2012;33:197 e121-132.

35. Dong Z, Yan L, Huang G, Zhang L, Mei B, Meng B. Ibuprofen partially attenuates neurodegenerative symptoms in presenilin conditional doubleknockout mice. Neuroscience. 2014;270:58-68.

36. Hillmann A, Hahn S, Schilling S, Hoffmann T, Demuth HU, Bulic B, Schneider-Axmann T, Bayer TA, Weggen S, Wirths O. No improvement after chronic ibuprofen treatment in the 5XFAD mouse model of Alzheimer's disease. Neurobiol Aging. 2012;33:833 e839-850.

37. Barlow C, Hirotsune S, Paylor R, Liyanage M, Eckhaus M, Collins F, Shiloh Y, Crawley JN, Ried T, Tagle D, Wynshaw-Boris A. Atm-deficient mice: a paradigm of ataxia telangiectasia. Cell. 1996;86:159-71.

38. Yan Q, Zhang J, Liu H, Babu-Khan S, Vassar R, Biere AL, Citron M, Landreth G. Anti-inflammatory drug therapy alters beta-amyloid processing and deposition in an animal model of Alzheimer's disease. J Neurosci. 2003;23:7504-9.

39. Lee J-K, Tansey MG. Microglia isolation from adult mouse brain. Methods Mol Biol. 2013:1041:17-23.

40. Hui CW, Zhang Y, Herrup K. Non-neuronal cells are required to mediate the effects of neuroinflammation: results from a neuron-enriched culture system. PLoS One. 2016;11:e0147134.

41. Combs CK, Johnson DE, Cannady SB, Lehman TM, Landreth GE. Identification of microglial signal transduction pathways mediating a neurotoxic response to amyloidogenic fragments of beta-amyloid and prion proteins. J Neurosci. 1999;19:928-39.

42. Wu Q, Combs C, Cannady SB, Geldmacher DS, Herrup K. Beta-amyloid activated microglia induce cell cycling and cell death in cultured cortical neurons. Neurobiol Aging. 2000;21:797-806.

43. Ang Z, Er JZ, Tan NS, Lu J, Liou YC, Grosse J, Ding JL. Human and mouse monocytes display distinct signalling and cytokine profiles upon stimulation with FFAR2/FFAR3 short-chain fatty acid receptor agonists. Sci Rep. 2016;6:34145

44. Ingersoll MA, Spanbroek R, Lottaz C, Gautier EL, Frankenberger M, Hoffmann R, Lang R, Haniffa M, Collin M, Tacke F, et al. Comparison of gene expression profiles between human and mouse monocyte subsets. Blood. 2010;115:e10-9. 
45. Chanput W, Mes JJ, Wichers HJ. THP-1 cell line: an in vitro cell model for immune modulation approach. Int Immunopharmacol. 2014;23:37-45.

46. Pietkiewicz S, Schmidt JH, Lavrik IN. Quantification of apoptosis and necroptosis at the single cell level by a combination of imaging flow cytometry with classical Annexin V/propidium iodide staining. J Immunol Methods. 2015:423:99-103.

47. Na YR, Yoon YN, Son D, Jung D, Gu GJ, Seok SH. Consistent inhibition of cyclooxygenase drives macrophages towards the inflammatory phenotype. PLoS One. 2015;10:e0118203.

48. Shakkottai VG, Chou CH, Oddo S, Sailer CA, Knaus HG, Gutman GA, Barish ME LaFerla FM, Chandy KG. Enhanced neuronal excitability in the absence of neurodegeneration induces cerebellar ataxia. J Clin Invest. 2004;113:582-90

49. Carnevale D, Mascio G, Ajmone-Cat MA, D'Andrea I, Cifelli G, Madonna M, Cocozza G, Frati A, Carullo P, Carnevale L, et al. Role of neuroinflammation in hypertension-induced brain amyloid pathology. Neurobiol Aging. 2012; 33:205 e219-229.

50. Huang ZJ, Hsu E, Li HC, Rosner AL, Rupert RL, Song XJ. Topical application of compound ibuprofen suppresses pain by inhibiting sensory neuron hyperexcitability and neuroinflammation in a rat model of intervertebral foramen inflammation. J Pain. 2011;12:141-52.

51. Milatovic D, Gupta RC, Yu Y, Zaja-Milatovic S, Aschner M. Protective effects of antioxidants and anti-inflammatory agents against manganese-induced oxidative damage and neuronal injury. Toxicol Appl Pharmacol. 2011;256:219-26.

52. Meunier J, Borjini N, Gillis C, Villard V, Maurice T. Brain toxicity and inflammation induced in vivo in mice by the amyloid-beta forty-two inducer aftin-4, a roscovitine derivative. J Alzheimers Dis. 2015;44:507-24

53. Jiang T, Zhang YD, Chen Q, Gao Q, Zhu XC, Zhou JS, Shi JQ, Lu H, Tan L, Yu JT. TREM2 modifies microglial phenotype and provides neuroprotection in P301S tau transgenic mice. Neuropharmacology. 2016;105:196-206.

54. Cherry JD, Olschowka JA, O'Banion MK. Neuroinflammation and M2 microglia: the good, the bad, and the inflamed. J Neuroinflammation. 2014;11:98

55. Herrup K, Yang Y. Cell cycle regulation in the postmitotic neuron: oxymoron or new biology? Nat Rev Neurosci. 2007;8:368.

56. Yang $Y$, Herrup K. Loss of neuronal cell cycle control in ataxia-telangiectasia: a unified disease mechanism. J Neurosci. 2005:25:2522-9.

57. Li J, Chen J, Ricupero CL, Hart RP, Schwartz MS, Kusnecov A, Herrup K. Nuclear accumulation of HDAC4 in ATM deficiency promotes neurodegeneration in ataxia telangiectasia. Nat Med. 2012;18:783-90.

58. Quek H, Luff J, Cheung KG, et al. Rats with a missense mutation in Atm display neuroinflammation and neurodegeneration subsequent to accumulation of cytosolic DNA following unrepaired DNA damage. J Leukoc Biol. https://doi.org/10.1189/jlb.4VMA0716-316R.

59. Quek H, Luff J, Cheung KG, et al. A rat model of ataxia-telangiectasia: evidence for a neurodegenerative phenotype. Hum Mol Genet. 2017;26(1): 109-23. https://doi.org/10.1093/hmg/ddw371.

60. McGrath-Morrow SA, Collaco JM, Crawford TO, Carson KA, Lefton-Greif MA, Zeitlin P, Lederman HM. Elevated serum IL-8 levels in ataxia telangiectasia. J Pediatr. 2010;156:682-4 e681.

61. Westbrook AM, Schiestl RH. Atm-deficient mice exhibit increased sensitivity to dextran sulfate sodium-induced colitis characterized by elevated DNA damage and persistent immune activation. Cancer Res. 2010;70:1875-84.

62. Härtlova A, Erttmann SF, et al. DNA damage primes the type i interferon system via the cytosolic dna sensor sting to promote anti-microbial innate immunity. Immunity. 2015;42(2):332-43.

63. Bo Hu, Chengcheng Jin et.al: The DNA-sensing AIM2 inflammasome controls radiation-induced cell death and tissue injury. Science 2016; 354(6313):765-768

64. Lee M, Suk K, Kang Y, McGeer E, McGeer PL. Neurotoxic factors released by stimulated human monocytes and THP-1 cells. Brain Res. 2011;1400:99-111.

65. Hohsfield LA, Ammann CG, Humpel C. Inflammatory status of transmigrating primary rat monocytes in a novel perfusion model simulating blood flow. J Neuroimmunol. 2013;258:17-26.

66. Spinas GA, Bloesch D, Keller U, Zimmerli W, Cammisuli S. Pretreatment with ibuprofen augments circulating tumor necrosis factor-alpha, interleukin-6, and elastase during acute endotoxinemia. J Infect Dis. 1991;163:89-95.

67. Valencia A, Moran J. Reactive oxygen species induce different cell death mechanisms in cultured neurons. Free Radic Biol Med. 2004:36:1112-25.

68. Ditch S, Paull $\Pi$. The ATM protein kinase and cellular redox signaling: beyond the DNA damage response. Trends Biochem Sci. 2012;37(1):15-22 https://doi.org/10.1016/j.tibs.2011.10.002.
69. Guo Z, Kozlov S, Lavin MF, Person MD, Paull TT. ATM Activation by oxidative stress. Science. 2010;330(6003):517-21. https://doi.org/10.1126/science. 1192912.

70. Ghosal K, Stathopoulos A, Pimplikar SW. APP intracellular domain impairs adult neurogenesis in transgenic mice by inducing neuroinflammation. PLoS One. 2010;5:e11866.

71. Lim GP, Yang F, Chu T, Chen P, Beech W, Teter B, Tran T, Ubeda O, Ashe KH, Frautschy SA, Cole GM. Ibuprofen suppresses plaque pathology and inflammation in a mouse model for Alzheimer's disease. J Neurosci. 2000;20: 5709-14.

72. Pinato L, da Silveira C-MS, Franco DG, Campos LMG, Cecon E, Fernandes PACM, Bittencourt JC, Markus RP. Selective protection of the cerebellum against intracerebroventricular LPS is mediated by local melatonin synthesis. Brain Struct Funct. 2015;220:827-40.

73. Grabert K, Michoel T, Karavolos MH, Clohisey S, Baillie JK, Stevens MP, Freeman TC, Summers KM, McColl BW. Microglial brain regiondependent diversity and selective regional sensitivities to ageing. Nat Neurosci. 2016;19:504-16.

74. Savchenko VL, McKanna JA, Nikonenko IR, Skibo GG. Microglia and astrocytes in the adult rat brain: comparative immunocytochemical analysis demonstrates the efficacy of lipocortin 1 immunoreactivity. Neuroscience. 2000;96:195-203.

\section{Ready to submit your research? Choose BMC and benefit from:}

- fast, convenient online submission

- thorough peer review by experienced researchers in your field

- rapid publication on acceptance

- support for research data, including large and complex data types

- gold Open Access which fosters wider collaboration and increased citations

- maximum visibility for your research: over 100M website views per year

At BMC, research is always in progress.

Learn more biomedcentral.com/submissions 